\title{
ADDRESSING THE LEGAL ISSUES OF AN INNOVATIVE START-UP COMPANY
}

BY

VLAD SAMOYLOV

\begin{abstract}
A thesis
submitted to the Victoria University of Wellington in partial fulfilment of the requirements for the degree of

Master of Advanced Technology Enterprise
\end{abstract}

Victoria University of Wellington

2014 


\section{Abstract}

Before examining the substance of the law it is necessary to discuss the contrast between law and practice. It is important to keep in mind that the letter of the law is sometimes not what is done in practice. This realisation is often referred to as the "law and society perspective." Advocates of this perspective treat legal doctrine as more than just a closed system because they recognise that there are other external influences at play. Beyond the law, people are also influenced by other factors such as social roles, morals, religion and culture. For example, university researchers have an external incentive mechanism outside of IP law. Such researchers frequently prefer to publish their results and discoveries in academic journals rather than file for patents. A patent cannot be granted where there has been a publication. However the researchers are motivated by other incentives such as access to research funds and the attainment of professorship.

The Law and Society perspective highlights the fact that the formal processes, which are provided for by the law are at times substituted by informal customs and understandings. An information technology (IT) firm that contributed to this paper by participating in an interview (Interviewee A), provided a good example of such an occurrence. Rather than use any of the formal IP modes of protection which are discussed in the following sections of this paper, 'Interviewee A' uses a very unorthodox strategy to protect their IP. They said: "we rely on employment contracts, code of conduct, and especially personal ethics and behaviour to protect our IP. We therefore have a company culture that encourages teamwork and cooperation". 


\section{Acknowledgments}

I would like to express my gratitude to Professor Susan Corbett. You have been a tremendous supervisor and mentor. Thank you for all your encouragement and support. Your advice and guidance has made it possible for me to finalise this thesis.

I would like to thank Dr Paul Smith for his efforts in coordinating the Master of Advanced Technology programme and for his guidance throughout the year. I also want to thank Professor Kathryn McGrath for establishing the programme and for giving me the opportunity to be part of it. I have truly appreciated your ongoing support and feedback. Also, thank you to Michael Elwood-Smith for providing professional advice and guidance in the programme.

Finally, I would like to thank all the companies I interviewed, for their contribution to my research. 


\section{Contents}

PART 1: Thesis.................................... 3

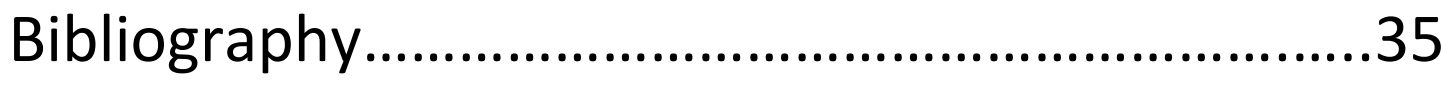

PART 2: Appendix.................................38

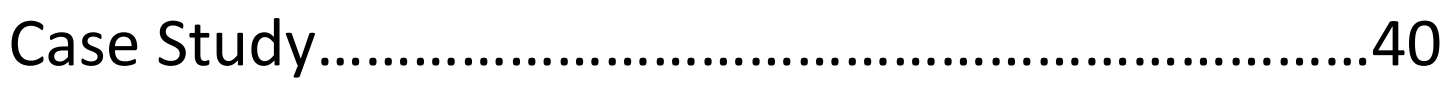

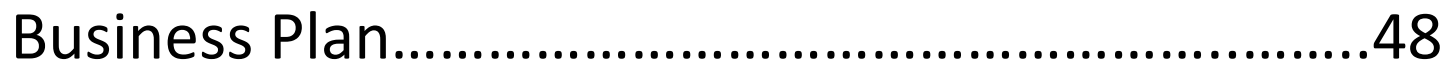

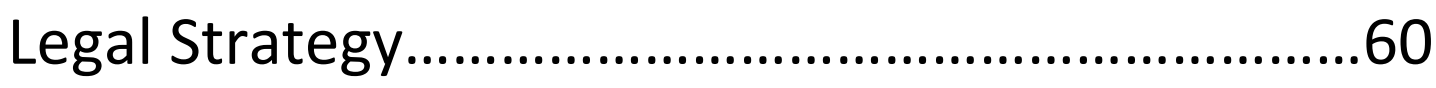




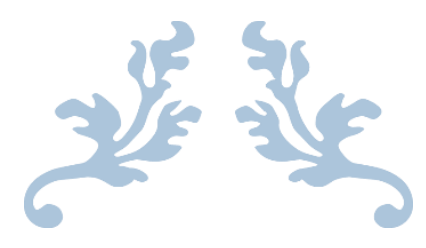

\section{PART 1: Thesis}




\section{Contents}

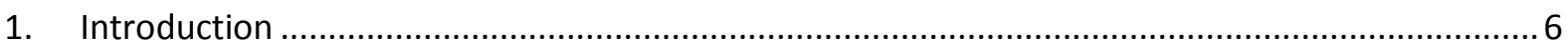

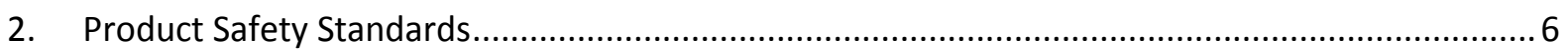

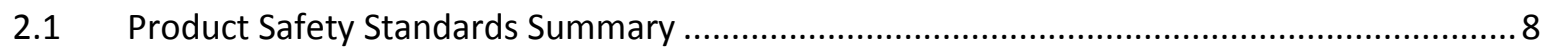

3. The Contrast between Practice and the Law ................................................................. 8

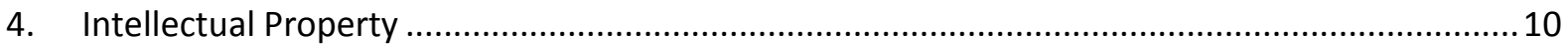

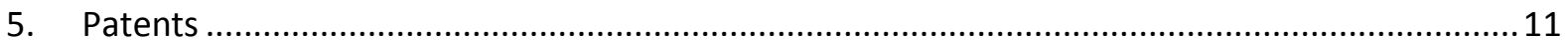

$5.1 \quad$ Patent Benefits.......................................................................................... 11

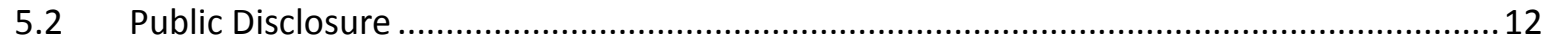

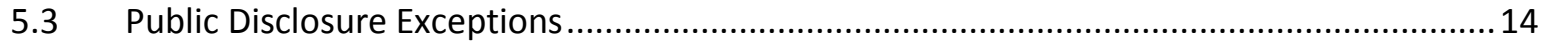

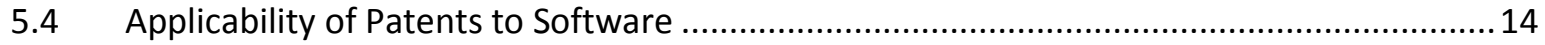

Effectiveness of Patent Protection Oversees............................................................ 15

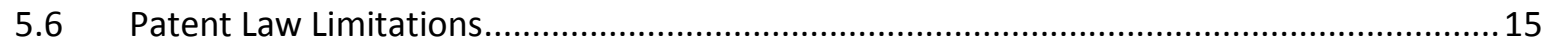

5.7 Patent strategies used by Manufacturing Companies ............................................... 16

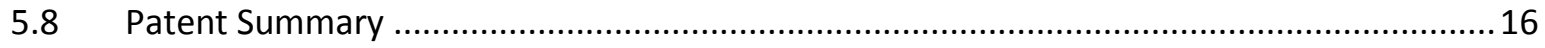

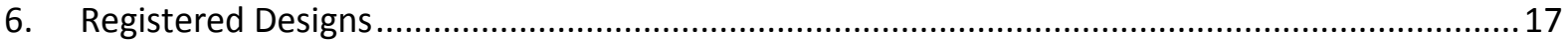

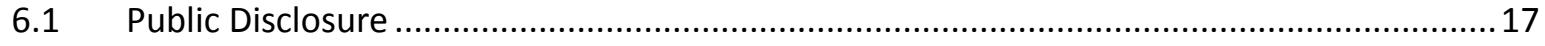

6.2 Public Disclosure Exceptions ............................................................................. 17

6.3 Determining what is Substantially Different? ....................................................... 18

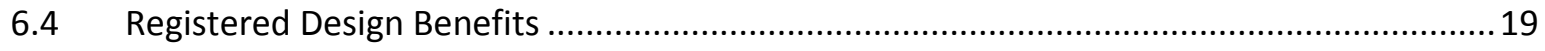

6.5 Effectiveness of Registered Design Protection Overseas .......................................... 19

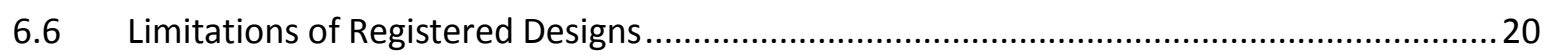

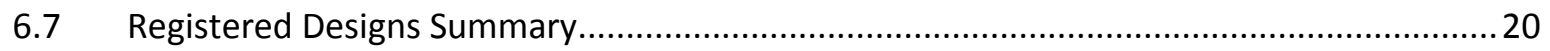

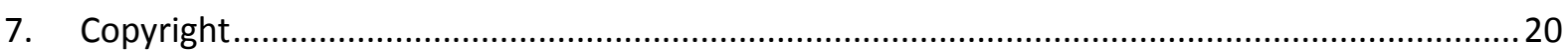

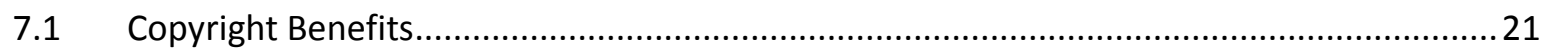

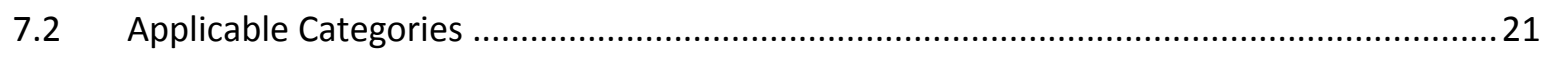

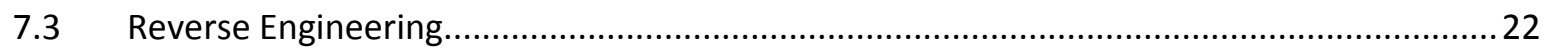

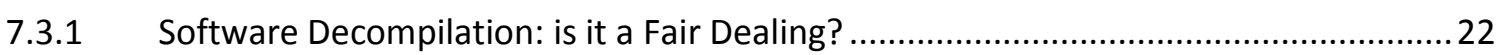

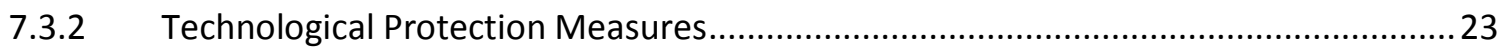

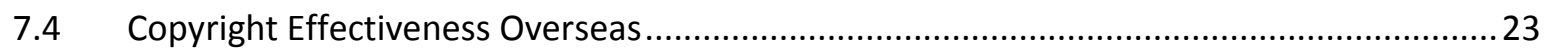

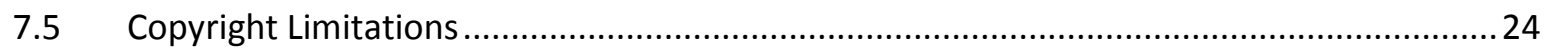

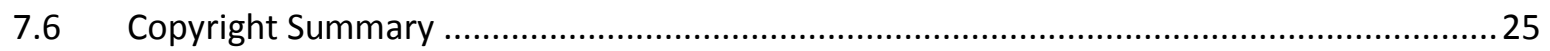

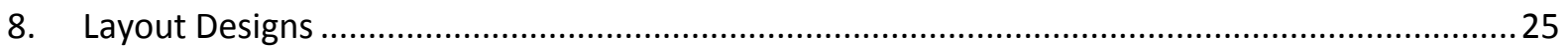

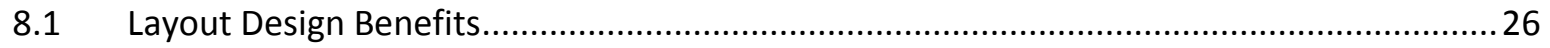

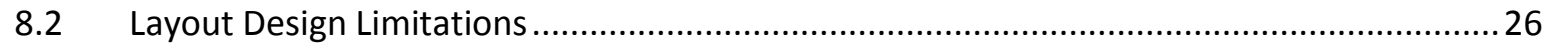

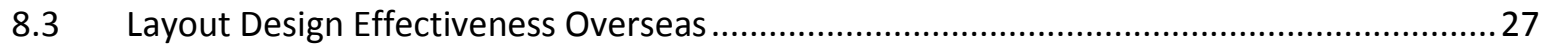




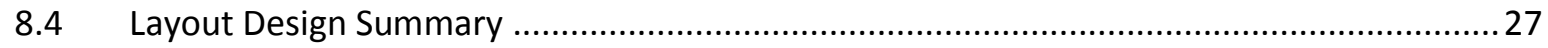

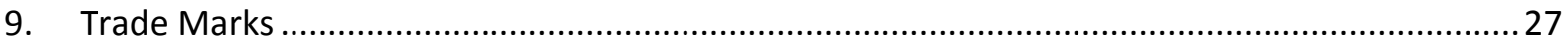

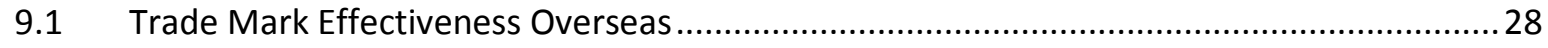

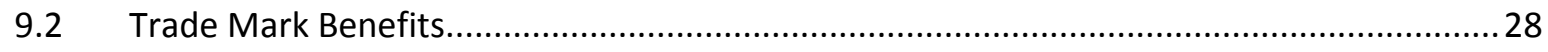

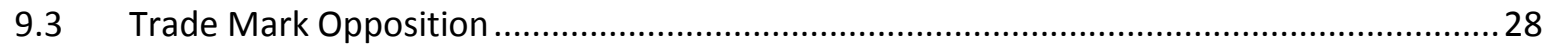

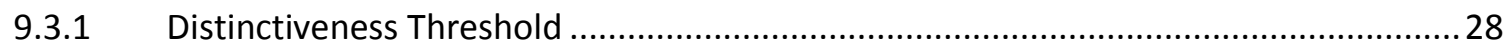

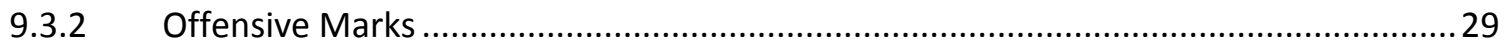

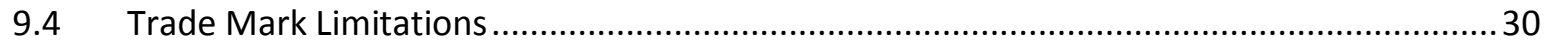

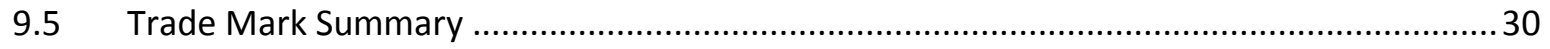

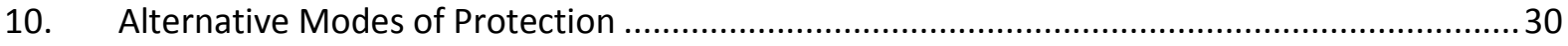

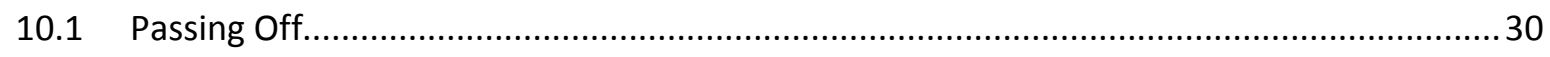

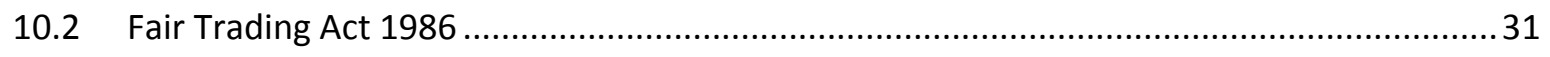

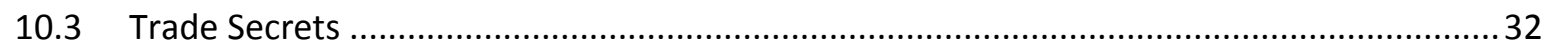

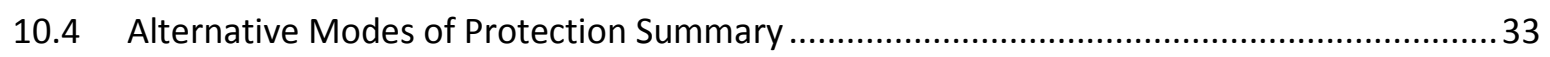

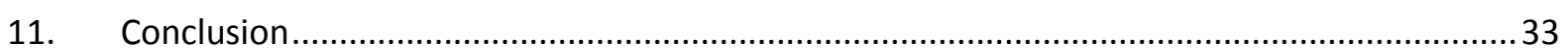

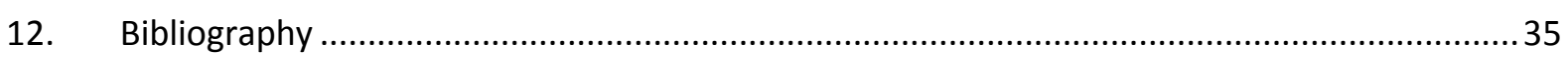




\section{Addressing the Legal Issues of an Innovative Start-Up Company}

\section{Introduction}

The focus of this paper is on the legal issues facing a university team (the team), which is investigating the commercial potential of a product designed by a graduate student (the project champion). ${ }^{1}$ The product is a toy (the toy) for children with autism. The first issue addressed is whether the toy is likely to comply with the laws around product safety standards. The much more pervasive issue discussed concerns Intellectual Property (IP) law. An issue of potential detriment to IP protection arose when the toy was disclosed in the public domain during the product development phase of the product's life cycle. Therefore this paper seeks to determine what modes of IP protection are lost or otherwise negatively affected by public disclosure in New Zealand (NZ) and whether there are any permitted exceptions.

This paper also discusses the strengths of IP protection measures which are available in NZ despite prior public disclosure; and identifies the limitations of each measure. The paper briefly touches on alternative means of protection as well. Different modes of protection will be examined in order to determine their level of effectiveness once a product becomes marketed overseas. Included is some discussion relating to the possibility of acquiring different modes of IP protection in the United States of America (US), as the team have identified it as a potential target market outside NZ.

Within individual sections of the paper are extracts from interviews with a selection of NZ companies that market their products overseas as well as domestically. ${ }^{2}$ The input of these companies is used for the purposes of providing the views of those who have experience dealing with legal issues in the commercial world.

\section{Product Safety Standards}

The Product Safety Standards (Toys) Regulations 2005 which is made under the Fair Trading Act 1986 (FTA) deems it necessary for toys intended for use by children who are up to 36 months of age to

\footnotetext{
${ }^{1}$ For more information on the team and the project please refer to the case study in the appendix.

2 Please note that the companies which were interviewed are referred to by general description only, as they agreed to participate on the basis that their names would not be revealed in this paper.
} 
comply with the Standard AS/NZS ISO 8124.1:2002. Any breach of the Standard means that the regulation is also breached and this is an offence under the FTA. ${ }^{3}$

The Standard was set in place in recognition of the fact that children under 36 months of age have not yet developed a coughing reflex. It prohibits the supply of small toys or toys with small parts, which can be swallowed or inhaled by children under 36 months of age. ${ }^{4}$ Generally any toy or toy part that is smaller than a ping pong ball or a $35 \mathrm{~mm}$ film canister will be in breach of the Standard. ${ }^{5}$

The toy in the case study is a large toy. However it contains multiple small parts on the interior. These parts are not meant to be removable, but the Standard states that toys must not have pieces that are capable of being broken off as a result of normal use or reasonably foreseeable abuse. A reasonably foreseeable abuse test simulates conditions in which abuse could occur. For example it is reasonably foreseeable that a small child may drop the toy as they are not yet able to grip and hold onto it. ${ }^{6}$ For the purposes of the team in the case study it may be necessary to also test the toy in conditions where it is thrown, as the toy is targeted at children with Autism, who are sometimes prone to such behaviour.

It is not possible to simply label the toy as not being suitable for children under 36 months of age. Whether the Standard is applicable to a toy is decided on a case by case basis, but generally the toy will be considered to have been designed for children under 36 months of age if there are factors which indicate that this is so. If the child is physically and intellectually capable of playing with the toy in the way it was intended to be used, then it will be deemed as a toy designed for children under 36 months of age. ${ }^{7}$ The toy in the case study is simple to use and testing with small children will likely show that they are capable of using the toy in the way in which it is meant to be used. Thus it is highly likely that the Standard will apply regardless of whether there is a minimum age label attached to the product.

Another potential breach of the Standard relevant to the toy relates to the fur that covers the toy. A potential choking hazard involving fur on a toy has been identified in the past. One example was where the Dulux Company gave away a free toy dog as a promotional gift, which came with purchases of

\footnotetext{
${ }^{3}$ Fair Trading Act 1986, s 30.

4 "Children's Toys: A Guide to Complying with the Product Safety Standard" (2009) Commerce Commission New Zealand at $1<w w w . c o m c o m . g o v t . n z>$.

${ }^{5} \mathrm{Ibid}$, at 2.

${ }^{6}$ Ibid.

${ }^{7}$ Ibid.
} 
certain products. However an investigation by the Commerce Commission established that the fur attached to the toy could be swallowed as a result of it coming apart when it was being pulled, chewed or sucked. ${ }^{8}$ Therefore it will be necessary to test the toy in the case study to ensure that the attached fur does not come away in the event that it is chewed, pulled or sucked.

\subsection{Product Safety Standards Summary}

The toy in the case study is a simple toy which is likely to be deemed appropriate for children under 36 months of age. As such, it is necessary to conduct tests to ensure that the product does not have small parts, which can break off as a result of reasonably foreseeable abuse by children with autism who are within that age group. The area of particular concern is the fur which covers the toy. Therefore it is important to ensure that this fur is sufficiently intact, or to find an alternative covering material altogether.

\section{The Contrast between Practice and the Law}

The next issue discussed relates to IP protection, but before examining the substance of the law it is necessary to discuss the contrast between law and practice. It is important to keep in mind that the letter of the law is sometimes not what is done in practice. This realisation is often referred to as the "law and society perspective. ${ }^{9}$ Advocates of this perspective treat legal doctrine as more than just a closed system because they recognise that there are other external influences at play. Beyond the law, people are also influenced by other factors such as social roles, morals, religion and culture. ${ }^{10}$ For example, university researchers have an external incentive mechanism outside of IP law. Such researchers frequently prefer to publish their results and discoveries in academic journals rather than file for patents. ${ }^{11} \mathrm{~A}$ patent cannot be granted where there has been a publication. ${ }^{12}$ However the researchers are motivated by other incentives such as access to research funds and the attainment of professorship. $^{13}$

\footnotetext{
8 "Dulux Recalls Toy Dogs after Complaint to Commerce Commission" (2012) Commerce Commission New Zealand <www.comcom.govt.nz>.

9 "Legal Theory: Law and Society" (2013) Berkman Center for Internet and Society $<$ www.cyber.law.harvard.edus.

${ }^{10} \mathrm{lbid}$.

${ }^{11}$ Roland Kirstein “Intellectual Property: Economic and Legal Dimensions of Rights and Remedies" (2006) 89(1) European Journal of Law and Economics 90 at 93.

12 Patents are discussed in section 5.

${ }^{13}$ Kirstein, above n 11, at 93.
} 
The Law and Society perspective highlights the fact that the formal processes, which are provided for by the law are at times substituted by informal customs and understandings. ${ }^{14}$ An information technology (IT) firm that contributed to this paper by participating in an interview (Interviewee A), provided a good example of such an occurrence. Rather than use any of the formal IP modes of protection which are discussed in the following sections of this paper, 'Interviewee A' uses a very unorthodox strategy to protect their IP. They said: "we rely on employment contracts, code of conduct, and especially personal ethics and behaviour to protect our IP. We therefore have a company culture that encourages teamwork and cooperation".

The above examples appear consistent with the historic standard of economic theory, which assumed that the law is not fundamental to the market because parties can simply negotiate to change any provisions of the law which prohibit them from taking the steps necessary to achieve maximum value of production. ${ }^{15}$ However this paper is concerned with business activities as the team in the case study are investigating the toy's commercial potential and so the circumstances are distinguishable from the university researchers' example. 'Interviewee A' on the other hand is clearly a business, but it chooses not to rely on any of the formal IP protection modes available under the law. Therefore this begs the question, whether the law is in fact of fundamental significance in business activities.

In answering this question it is important to note that the conditions assumed by the historic standard of economic theory are in fact quite imaginary. In the real business world there are substantial transaction costs, which include the maintenance of trust, minimisation of risk and the establishment of certainty.${ }^{16}$ In terms of IP, the law identifies and protects a set of intangible resources that are transferrable in the market. It identifies what is mine and what is yours and secures the benefit to the owner, in the event of a business transaction. ${ }^{17}$ In reality the rights and duties of the owner are to a very large extent determined by the law. ${ }^{18}$ Therefore legislation is in fact fundamental in business practice, but how then does one explain 'Interviewee A's' choice to rely on a strategy that ignores the formal protection measures? Perhaps the most straight forward answer is a quote from the interviewee: "our IP is in our detailed technical designs and people's knowledge". As such, the example

\footnotetext{
14 "Legal Theory: Law and Society", above n 9.

15 O Lee Read "Law, The Rule of Law, and Property: A foundation for the Private Market and Business Study" (2001) 38(3) American Business Law Journal 441 at 466.

$16 \mathrm{lbid}$, at 465 .

17 Ibid, at 451.

$18 \mathrm{Ibid}$, at 466.
} 
is distinguishable from the circumstances in the case study scenario. The IP related to the toy is identifiable through the process of reverse engineering, whereas 'Interviewee A's' IP is not contained within their products, but is in the intellectual capital of the company. Therefore for the purposes of the case study and for most other kinds of IP, the formal methods of protection provided by the law are absolutely fundamental when the product is to be commercialised.

The law and society perspective assumes that not all actions are dictated by the law. Advocates of the approach view societies' behaviour within the broader social context in which it occurs. ${ }^{19}$ The perspective is also theoretically applicable to commercial law. However in the business world the legal system has such a substantial effect on the workings of the economic system that it can essentially be said to shape and control it. ${ }^{20}$ To say that IP would cease to exist without the law is an accurate statement, which illustrates the profound effect that the legal system has on the marketplace. ${ }^{21}$ As such, it is important to examine the law around the different modes of IP protection. These will be discussed individually in the following sections.

\section{Intellectual Property}

IP describes the unique ideas and creations which are produced as a result of human creativity. ${ }^{22}$ In today's world recognition of the importance of IP is growing at such a rate that it often surpasses the value of a business's other assets. Therefore one can easily appreciate why so many companies put sufficient effort into protecting their IP. After all, the state of a company's IP frequently determines its market share and influence.

The quantity and quality of a business's IP directly impacts the company's reputation and its access to the market as well as many other factors. Thus IP is a clear sign of a company's competitiveness. ${ }^{23}$ On the other hand, it has long been the popular view that free competition is the norm in the economy,

\footnotetext{
${ }^{19}$ Lee Epstein and Jack Knight "Building the Bridge from Both Sides of the River: Law and Society and Rational Choice" (2004) 38(2) 207 at 209.

${ }^{20}$ Read, above $\mathrm{n} 14$, at 466.

${ }^{21} \mathrm{Ibid}$, at 453.

${ }^{22}$ A Dumi, Z Sinaj and M Nuhiu “Intellectual Property Rights and Economic Development" (2012) 2 Journal of Educational and Social Research 321 at 322.

${ }^{23}$ Donal O'Connell "Why Intellectual Property Matters: The Growing Importance of Intellectual Property" (2013) Imperial College London <www3.imperial.ac.uk>.
} 
while intellectual property rights are only an exception to that norm. ${ }^{24}$ In NZ the exception is provided for in the Commerce Act 1986 which states that a person does not take advantage of a substantial degree of market power by reason only that they seek to enforce an IP right. ${ }^{25}$ IP law grants exclusive rights to the originators of ideas, giving them a legal exception to the general rule of free competition. For example a patent is a type of IP protection mode that provides an inventor with a monopoly in their invention for a period of 20 years. ${ }^{26}$ Thus a patent is essentially a contract between an individual inventor and society, which provides the inventor with exclusive rights in exchange for disclosing the details of their invention to the public. ${ }^{27}$ Such exceptions exist due to the societal recognition that safeguarding IP rights results in economic growth and creates incentives for innovation. ${ }^{28}$ Businesses by nature are primarily profit-seeking entities and as such it is only natural that they capitalise on the exception.

\section{Patents}

A patent is one form of IP protection. The basic requirements for a patent are that the invention is new, useful, non-obvious and it must involve an inventive step. ${ }^{29}$ The requirement that an invention is new indicates that the right to register a patent in that invention is lost upon it being disclosed in the public domain. The basic requirements for a patentable invention are the same in the Patents Act 2013 (2013 Act) as they are in the Patents Act 1953 (1953 Act). ${ }^{30}$ However only Part 1 of the 2013 Act is currently in force. Therefore references will be made to both the 1953 Act and the 2013 Act for the sake of completeness.

\subsection{Patent Benefits}

In order to identify what exactly is lost by prior public disclosure, it is necessary to discuss the benefits of patent protection and give an explanation of what a patent is typically used for. A patent is perhaps the strongest form of IP protection. This is because a patent gives the patent holder exclusive rights

\footnotetext{
${ }^{24}$ Mark Lemley and John Duffy "Property, Intellectual Property, and Free Riding/Comment/Reply" (2005) 83 Texas Law Review 1031 at 1031.

${ }^{25}$ Commerce Act 1986, s 36(3).

${ }^{26}$ Patents are discussed in section 5.

${ }^{27}$ Thomas Field "What is Intellectual Property?" (2008) IIP Digital <www.iipdigital.usembassy.gov>.

${ }^{28}$ Ibid.

${ }^{29}$ Patents Act 1953, s 21.

30 Patents Act 2013, s 14.
} 
including the sole right to manufacture and sell the invention. Thus in effect it gives the patentee the right to exclude others from the relevant market and hold a monopoly in that market for 20 years from the date of the patent. ${ }^{31}$ The term of a patent is the same in the 2013 Act. $^{32}$ In fact patent protection is so strong that neither independent invention nor reverse engineering gives competitors the right to use a patented invention for commercial purposes. Competitors do not even have the defence of genuine ignorance to the existence of the patent, available to them. ${ }^{33}$ Furthermore one can acquire a patent in multiple countries. A small manufacturing enterprise, which manufactures household safety items and operates in a small number of countries including the US (Interviewee B), had this to say: "patents are absolutely key because for every new market we went into we sought a patent before going in and that was our best form of product protection."134

In recognition of these benefits, the most pressing issue for the purposes of this paper is whether the invention in the case study scenario was in fact disclosed to the public prior to a patent application being filed.

\subsection{Public Disclosure}

Prior publication is one way in which public disclosure occurs. Any such prior publication must have been available in NZ before the priority date of the patent claim. ${ }^{35}$ Publications include those that were produced by others as well as those produced by the applicant. ${ }^{36}$

The 1953 Act states that publications which are not available in NZ are irrelevant. ${ }^{37}$ However in Molecular Plant Breeding Nominees Ltd v Vialactia Bioscience (NZ) Ltd ${ }^{38}$, the commissioner held that a document which is proven to have been accessible in New Zealand, such as an overseas website, will

\footnotetext{
${ }^{31}$ Patents Act 1953, s 30(3).

32 Patents Act 2013, s20(1).

${ }^{33}$ William Caenegem Intellectual Property Law and Innovation (Cambridge University Press, New York, 2007) at 60 .

${ }^{34}$ Further discussion on patent effectiveness in overseas markets can be found in section 5.5.

${ }^{35}$ Greg Arthur and Matt Sumpter "Intellectual Property for Non-Specialists" (paper presented to New Zealand Law Society Seminar, Wellington, August 2008) at 47.

${ }^{36}$ Caenegem, above $\mathrm{n} 31$, at 80.

37 Patents Act 1953, s 21(1)(b).

38 Molecular Plant Breeding Nominees Ltd v Vialactia Bioscience (NZ) Ltd (IPONZ, Assistant Commissioner Popplewell, 12 September 2005).
} 
be relevant in assessing obviousness and whether or not there has been prior publication. ${ }^{39}$ Furthermore the 2013 Act provides that any disclosed information about the invention whether in NZ or elsewhere will be relevant in determining whether it is novel. ${ }^{40}$

In patent law the "reverse infringement" test is the test that is universally cited for determining whether or not there has been a publication. The test is set out in General Tire \& Rubber Company $v$ Firestone Tyre \& Rubber Company Ltd. ${ }^{41}$ McKenzie J summarised the test well in Sealed Air New Zealand Limited $v$ Machinery Developments Limited ${ }^{42}$, where he stated that the prior publication must describe something that would infringe the claim; or must instruct how something should be done or made which would infringe the claim; or must give directions that would inevitably result in an infringement, upon being carried out. ${ }^{43}$ Thus in essence the test recognises that a particular invention may be described in different words, but if the description is such that upon adherence to the instructions one would infringe the claim, than the claim will be deemed invalid.

This case law is still likely to apply under the 2013 Act, only it may be applicable to a broader range of disclosure types, rather than just prior publication. The 2013 Act accepts a very wide range of public disclosure. It states that disclosure can be written or oral and can occur by use or in any other way. ${ }^{44}$

There must be prior disclosure for an application to be invalidated. However it is irrelevant whether members of the public actually accessed the information..$^{45}$ In patent law there must be absolutely no public disclosure, no matter how obscure its location and irrespective of how few members of the public actually access it. ${ }^{46}$

\footnotetext{
${ }^{39} \mathrm{lbid}$, at 27.

40 Patents Act 2013, s 8(1).

${ }^{41}$ General Tire \& Rubber Company v Firestone Tyre \& Rubber Company Ltd [1972] RPC 457 at 485/486.

42 Sealed Air New Zealand Limited v Machinery Developments Limited (unreported, High Court, Wellington, CIV2003-485-2274, 25 August 2004.

${ }^{43} \mathrm{Ibid}$, at [16].

${ }^{44}$ Patents Act 2013, s 8(1).

${ }^{45}$ Caenegem, above n 31, at 82.

${ }^{46} \mathrm{Ibid}$, at 35.
} 


\subsection{Public Disclosure Exceptions}

The exceptions to public disclosure are listed in section 9 of the 2013 Act. For the purposes of the toy in the case study the exceptions do not apply. However, upon discovery that there were no applicable exceptions, it also became apparent that what was unpatentable was only the information that existed at the time the product was disclosed. In the case study scenario, the product was merely an early prototype. Some elements which were planned to be incorporated into the final product, did not exist yet. Therefore a patent may be able to be obtained in features that have since been developed. This was suggested by an interviewee from a medium sized multinational company which specialises in children's equipment and is involved in 43 countries including the US (Interviewee C). They said: "prior public disclosure is not fatal. As you develop the product, resolve it and add benefits to it, you will potentially find other unique features."

\subsection{Applicability of Patents to Software}

One feature that had not been developed when the toy prototype was disclosed, was software. The current law in relation to IP protection of computer programs can be found in the 2013 Act. According to the new legislation software, as such, is no longer a patentable invention. ${ }^{47}$ The change came in recognition of the fact that the patent system was simply inappropriate for software, as it has become almost impossible to create new software without some existing software patent being breached. This is because there are hundreds and thousands of existing software patents, which are often for very obvious work. ${ }^{48}$ Nonetheless the Act states that an application will only be denied if the invention lies solely in the computer program. ${ }^{49}$ Therefore inventions which have embedded software are still likely to remain patentable. Although the software is certainly planned to be an embedded feature of the toy in the case study, it is unlikely to be patentable because the toy itself was already disclosed to the public. In other words the software cannot be protected because the invention itself is not patentable. However there are other features still being developed that did not exist at the time of the prior public disclosure, which are not software. The software will be just one of the features, which will be embedded in the finished product.

However this brings one to the next logical question, should a patent be obtained for these other features? For the purposes of answering this question it is necessary to discuss the effectiveness of patent protection overseas as well as identify the limitations of patent law. Furthermore the opinions

\footnotetext{
47 Patents Act 2013, s 11.

${ }^{48}$ Randal Jackson "Patents Bill Passes into Law" (2013) Computer World the Voice of IT Management $<w w w . c o m p u t e r w o r l d . c o . n z>$.

49 Patents Act 2013, s 11(3).
} 
of existing manufacturing companies as to their preference for this mode of protection, or lack thereof will also be discussed.

\subsection{Effectiveness of Patent Protection Oversees}

In the event that the product champion in the case study chooses to licence to, or incorporate into a joint venture with an overseas company, such a company is likely to prefer a patented product. 'Interviewee C' had this to say on the subject: "One of the first things a potential partner looks at is how defensible is the proposition? Can you lock out the competitors? Can you own the space? Can you own the category? Owning the category, if it is a substantial category is everything." A patent is usually viewed as evidence of exclusive category ownership by potential partners.

Most countries including NZ and the US are signatories to the Paris Convention. Therefore a patent is obtainable in the US within 6 months of the date that a patent application has been filed in New Zealand, provided that the requisite costs are paid and the necessary US patent requirements are met. $^{50}$

\subsection{Patent Law Limitations}

An obvious practical limitation of patent protection is that very few start-up companies benefit from obtaining this mode of protection. ${ }^{51}$ However novice entrepreneurs are often very nervous about novel ideas leaking into the public domain. 'Interviewee $C^{\prime}$ described the phenomenon as follows: "They start up a small business and think their idea is going to be huge, but far too many people spend all their money on patents and then they don't have any money to develop their business". An interviewee from a medium sized enterprise in the industrial sector that has a significant presence in NZ, Australia and the US (Interviewee D), explained the high costs associated with patents. They said: "the problem with a patent is that it costs a lot to undertake and yet it can be very easily challenged. Therefore you have to be able to defend it because not many companies can afford to fund an action against a multinational that may have encroached on it."

Therefore although start-up manufacturing companies protect their intellectual property with a range of mechanisms, of these, patents seem to be the least emphasised, while trade secrets appear to be

\footnotetext{
${ }^{50}$ Arthur and Sumpter, above n 33, at 9.

${ }^{51}$ Guido Westkamp (eds) Emerging Issues in Intellectual Property: Trade, Technology and Market freedom (Edward Elgar, Cheltenham, 2007) at 130.
} 
the most highly emphasised. ${ }^{52}$ 'Interviewee $D$ ' explained how one can stay on top of the competition without acquiring patent protection. They said: "If you have the ability to cost effectively innovate and to stay ahead you could possibly avoid it because by the time the product is stolen, it is likely to be an outdated version. Generally we tend to stay ahead of the technology and keep developing solutions ourselves."

\subsection{Patent strategies used by Manufacturing Companies}

On the other hand, there are other manufacturing companies which are reliant on patent protection. Many computer software companies have been reliant on patent protection rather than solely on copyright due to the fact that advances in technology have made software decompilation significantly easier. ${ }^{53}$ Of course NZ software companies are no longer able to acquire such protection under the new patent law.

There has also been an increase of larger companies using patents as strategic tools and not necessarily as a protection method. For example a company may have little commercial application from one invention, but when this is one of many acquired as part of a closely interwoven net of patents, the company dominates the market because this allows it to erect barriers to entry. ${ }^{54}$

\subsection{Patent Summary}

Patents are largely underused in the manufacturing industry as in many cases the expense seems unjustified in light of the benefit. However a patent does seem to be preferable when a product contains a non-obvious novel feature. Furthermore potential licencing or joint venture partners are far more likely to get on board if the IP is sufficiently protected, which usually means patent protection. This is especially so, when the relevant product is susceptible to reverse engineering.

In relation to the toy in the case study, it is obvious that public disclosure had occurred as the product's design together with general information about it, had been published on the internet by the project champion. Further specified information was also accessible via an information pamphlet written by the project champion, which was accessible to all attending an exhibition at which the product was

\footnotetext{
${ }^{52}$ Wesley Cohen, Richard Nelson and John Walsh "Protecting Their Intellectual Assets: Appropriability Conditions and Why U.S. Manufacturing Firms Patent (or Not)" (NBER Working Paper No. 7552) at 2.

${ }^{53}$ Robert Ostergard "The Measurement of Intellectual Property Rights Protection" (2000) 31(2) Journal of International Business Studies 349 at 349. (For further discussion on Copyright and software decompilation please also see section 7.)

${ }^{54}$ Caenegem, above n 31, at 67.
} 
revealed to the public. However a patent is still potentially obtainable for features that have been developed since the disclosure.

\section{Registered Designs}

The registered design is the other mode of IP protection which is lost in NZ in the event of public disclosure prior to registration. The necessary requirements for a valid registration are that the design must be new and original. Where a design is not new or original, it cannot be registered. A design is not new or original if it is the same as a design that had been previously registered or published in NZ. Furthermore the design that seeks protection must not only differ from a previous design in immaterial detail or merely through features that are common variants used in the relevant trade. ${ }^{55}$ This is of course similar to the inventive step requirement in patent law.

Registered designs protect features of configuration, shape, pattern or ornament, which are applied to a product by an industrial means or process. The protection does not extend to the principal or method of construction. The particular feature must be capable of being judged solely by the eye. ${ }^{56}$

\subsection{Public Disclosure}

For the purposes of the case study it is necessary to determine whether public disclosure had occurred prior to registration. In NZ novelty is destroyed if the design is made public in any way. Thus novelty may be successfully destroyed by a one-off showing to someone not under a confidentiality agreement. ${ }^{57}$ To this day, the design of the toy has not been registered and as mentioned previously, it has been published on the internet. Therefore it is clear that novelty has been destroyed, unless of course one of the statutory exceptions is applicable to the circumstances in the case study.

\subsection{Public Disclosure Exceptions}

The Designs Act 1953 provides a number of exceptions to the stringent rule of novelty. One such exception dictates that in certain circumstances there may be an implicit agreement that the disclosure was confidential. Therefore registration will not be invalidated in the event that disclosure was produced by another party in breach of good faith. ${ }^{58}$ Another exception is where the design is

\footnotetext{
55 Designs Act 1953, s 5(2).

${ }^{56}$ Arthur and Sumpter, above n 33, at 29.

${ }^{57}$ Paul Sumpter Intellectual Property Law: Principles in Practice ( ${ }^{\text {nd }}$ ed, $\mathrm{CCH}$ New Zealand Limited, Auckland, 2013) at 292.

${ }^{58}$ Designs Act 1953, s 10(1).
} 
disclosed at an approved exhibition. ${ }^{59}$ The disclosure will likewise not invalidate the registration if it was made to a government department or a person authorised by a government department for the purposes of evaluation. ${ }^{60}$

Unfortunately the exceptions do not apply to the case study as disclosure was not made at an approved exhibition, nor was the information only disclosed to authorised persons. Moreover it is not feasible to suggest that publication on the internet carries an implicit obligation of confidence.

However prior public disclosure does not necessarily rule out registered designs as a possible mode of protection. This is due to the fact that the requirement for registration is that the design is substantially new or original. The owner of a previously disclosed design may thus once again create a design that qualifies as being substantially different from previous designs if they use some of the already disclosed features together with new features. Such a design is capable of registration, as long as the appearance of the design as a whole is novel. ${ }^{61}$ Nonetheless this requirement appears to be quite stringent in practice. 'Interviewee $C^{\prime}$ had the following experience: "We tried to register how our product looked, but unfortunately we were unsuccessful. It was not believed to be sufficiently novel even though we thought we had something new and original on our hands."

\subsection{Determining what is Substantially Different?}

In order to determine what is substantially different from that which has been done before, the design must be looked at as a whole. In Sutton v Bay Masonry Limited ${ }^{62}$, Williams J said that for a registration to be valid there must be substantial novelty in that design. However the design does not necessarily have to be absolutely new or original, but it must be at least substantially new or original. Whether the design is in fact substantially new or original is a matter of fact that can only be determined by the eye. ${ }^{63}$

In UPL Group Limited v Dux Engineers Limited ${ }^{64}$, the Court said that in the event of substantial novelty or originality, minor variations in an allegedly infringing article will be unlikely to negate the infringement. On the other hand if there is little novelty or originality, than the allegedly infringing

\footnotetext{
${ }^{59}$ Designs Act 1953, s 10(2).

${ }^{60}$ Designs Act 1953, s 10(3).

${ }^{61}$ Sumpter, above n 55, at 295.

${ }^{62}$ Sutton v Bay Masonry Limited unreported, High Court, Tauranga CIV 2003-470-260, 28 May 2004.

${ }^{63} \mathrm{lbid}$, at [17].

${ }^{64}$ UPL Group Limited v Dux Engineers Limited [1989] 3 NZLR 136.
} 
article may avoid liability, even when there are only small differences from the registered design. Therefore this reasoning indicates that the essential need for novelty means that the level of protection provided for the design is determined in light of existing work the time of registration. Thus in the event that a design has relatively minimum originality in comparison to previous designs, small differences in future designs will likely be enough to avoid infringement. ${ }^{65}$

In applying this reasoning to the circumstances in the case study, it is reasonable to conclude that if changes are made to the design of the toy to the extent that it is once again substantially novel for the purposes of registration; potential competitors would be likely to escape liability by making minor variations to the design, due to the original design being in the public domain. Therefore following this line of reasoning it would seem that it is necessary to make drastic changes in the design in order to acquire adequate protection.

This of course begs the question, why would one go to such lengths in order to acquire this mode of protection? To answer this question, it is necessary to examine the benefits and limitations of registered designs.

\subsection{Registered Design Benefits}

A significant benefit of having a registered design is that the registered owner is not required to show evidence that actual copying occurred if there is an alleged infringement of the design, as opposed to copyright where this is necessary. With a registered design, substantial similarity is enough for infringement. ${ }^{66}$ As such this mode of protection is similar to a patent in the sense that the registered owner acquires a monopoly upon registration. ${ }^{67}$

\subsection{Effectiveness of Registered Design Protection Overseas}

The other potential advantage of obtaining a registered design as opposed to only having copyright protection is that the copyright laws of most countries, unlike NZ, do not provide protection for industrial designs. ${ }^{68}$ For example in the US there is no equivalent to the category of "industrially applied artistic work".

\footnotetext{
65 John Skinnon and John McDermott (eds) Law of Marketing in New Zealand ( ${ }^{\text {nd }}$ ed, Butterworhts, Wellington, 2001) at 255.

${ }^{66}$ Caenegem, above $\mathrm{n} 31$, at 162

${ }^{67}$ Sumpter, above n 55, at 283.

$68 \mathrm{lbid}$, at 284. (Also see discussion on copyright and industrially applied artistic works in section 7.)
} 
US copyright law requires the elements of a design to be the product of artistic judgment which is separable from functional considerations. ${ }^{69}$ However, equivalent protection to that of $\mathrm{NZ}$ is provided for in the US in the form of a design patent. ${ }^{70}$ The design patent is essentially the same as a registered design in NZ. The difference is that NZ identifies registered designs as an independent mode of IP protection, whereas the US includes registered design protection within the scope of their patent law.

\subsection{Limitations of Registered Designs}

Registered Designs are not meant to protect the functional elements of a product. ${ }^{71}$ Therefore registering a design will not prevent a potential competitor from reverse engineering the functional features of a product.

\subsection{Registered Designs Summary}

A registered design is useful when a product has a unique feature of configuration, shape or pattern that is worthy of protection. However it is not a suitable mode of protection for the functional elements of a product. Manufacturing companies that want to protect the design of their product tend to register the design if they are selling it overseas as well as NZ. This is due to the fact that NZ copyright protection of industrial designs made in three dimensions for the purposes of sale and hire is not reciprocal with most other countries.

In relation to the toy in the case study a registered design may still be obtainable if substantial changes are made to the design that existed during the public disclosure. In the event that the forthcoming testing proves that interaction between the children and the toy is primarily successful due to functional features, the design should be changed and registered. The team should then be able to obtain a design patent if they decide to enter the US market.

\section{Copyright}

In NZ copyright is acquired when one creates an original "work" as defined in the Copyright Act 1994. "Original" means that the work was independently made and not copied from a work that had been previously created. ${ }^{72}$ The creative expression must have been produced as a result of the exercise of

\footnotetext{
${ }^{69}$ Copyright Act 17 U.S.C. $§ 101$.

${ }^{70}$ Patents Act 35 U.S.C. § 173.

${ }^{71}$ Arthur and Sumpter, n 33, at 30.

${ }^{72}$ Copyright Act 1994, s 14.
} 
skill, judgment and effort. If the work is of very little original quality, than a very minimal change may be enough to avoid infringement. ${ }^{73}$ The scope of copyright protection is limited to the expression of an idea and not the idea itself, otherwise it would impede on the free flow of information and its legitimate use. ${ }^{74}$ In this sense, copyright is similar to registered designs because as mentioned in the previous section, registered design protection does not extend to functional features as that would mean protecting more than just an expression of a particular idea. Therefore it is necessary to compare the benefits of each mode in order to identify the differences.

\subsection{Copyright Benefits}

Registration is not required in NZ or any other member of the Berne Convention because member states are not permitted to require registration as a condition of copyright protection. Therefore prior public disclosure is irrelevant when it comes to copyright. ${ }^{75}$ It is arguable that when a business is operating solely in the domestic market, the protection of copyright is better than that of registered designs. This argument may be evidenced by the fact that few designs are registered in NZ as most manufactures prefer to rely on copyright protection. ${ }^{76}$ This is due to the fact that the creator of an original work receives automatic subsistence in copyright and thus incurs no expense. However NZ copyright protection does not necessarily extend into foreign countries. Therefore manufacturing companies exporting overseas are more likely to also use the registered designs mode of protection.

\subsection{Applicable Categories}

One does acquire automatic copyright protection in an original work, but the work must fit within one of the delineated categories specified in the Copyright Act $1994 .{ }^{77}$

There are three categories which are potentially applicable to the toy in the case study. The first is: "industrially applied artistic work". The time span of protection under this category is sixteen years from the date when more than fifty copies of the work have been made in three dimensions for the purpose of sale or hire. ${ }^{78}$

\footnotetext{
${ }^{73}$ Henkel KGaA v Holdfast New Zealand Ltd [2007] 1 NZLR 577 (SC) at [38].

${ }^{74}$ Westkamp, above $\mathrm{n} 49$, at 61.

${ }^{75}$ Sumpter, above n 55, at 12 .

${ }^{76}$ Skinnon and McDermott, above n 63, at 256.

${ }^{77}$ Copyright Act 1994, s 14.

${ }^{78}$ Copyright Act 1994, s 75(4)(a).
} 
The second potential category is: "work of artistic craftsmanship". It is far less likely that the toy in the case study can be categorised as such. However it would be favourable as this type of copyright lasts for 25 years from the time when the work was made. ${ }^{79}$ For a work to be regarded as one of artistic craftsmanship it must be possible to say that the author was both a craftsman and an artist. ${ }^{80} \mathrm{~A}$ craftsman is a person who makes something in a skilful way and takes justified pride in their workmanship. An artist is a person with creative ability who produces something which has aesthetic appeal. $^{81}$

The third category will be applicable to the toy once the software is created. In NZ, computer programs are included in the definition of literary works. Therefore software can be protected under the Copyright Act $1994 .^{82}$

\subsection{Reverse Engineering}

Regardless of which category the work falls under, Copyright protection does not prohibit reverse engineering. With literary works such as plays and novels, it is a non-issue. Whether by way of viewing or reading, everyone who uses the work as per its intended purpose is free to analyse the format and the different components that make up the work. However it is not so simple when it comes to some other types of work. In some works, a whole set of different considerations apply because most of the ideas and concepts that went into the creation of these are not evident at face value. ${ }^{83}$ Therefore in order to analyse the features of a work such as computer software, a person must go beyond the surface and look into its internal parts. ${ }^{84}$

\subsubsection{Software Decompilation: is it a Fair Dealing?}

In New Zealand any user who has lawfully obtained a copy of a computer program is permitted to decompile that program. ${ }^{85}$ Decompilation is permitted only for obtaining the necessary information for the purposes of creating an independent program, which can be operated with the decompiled

\footnotetext{
${ }^{79}$ Copyright Act 1994, s 75(1)(c).

${ }^{80}$ Bonz Group (Pty) Ltd v Cooke [1994] 3 NZLR 216, at 224.

81 Ibid.

${ }^{82}$ Sumpter, above $\mathrm{n} 55$, at 11.

${ }^{83} \mathrm{Ibid}$, at 6.

${ }^{84}$ Ibid, at 21.

${ }^{85}$ Copyright Act 1994, s 80A(1).
} 
program or with another program. ${ }^{86}$ However there is also an alternative means of protection that is sometimes used to prevent software decompilation called a Technological Protection Measure (TPM).

\subsubsection{Technological Protection Measures}

A TPM is a permitted protection measure in New Zealand. It is a technological means, treatment, mechanism, device or system that operates to prevent copyright infringement. ${ }^{87}$ TPMs allow software vendors to control the type of use that the purchaser, may effectively make of the software. In addition to preventing copyright infringement, software vendors often also try and prevent legitimate use such as decompilation using this method.

Another permitted protection measure is called Copyright Management Information (CMI). In New Zealand a copyright holder is permitted to embody or attach to their work information identifying the terms and conditions for its use. ${ }^{88}$ Prospective customers are prohibited from removing or modifying CMIs. $^{89}$

However, even though TPMs and CMIs are legal in NZ they are not an effective means of protection if one wishes to prevent software decompilation. Therefore this protection mechanism is not appropriate for the purposes of preventing decompilation of the toy's future software in the case study because potential competitors will be legally permitted to use a circumvention device. This is because circumvention devices are permitted whenever the software vendor uses the technological protection measure as a barrier to prevent the exercise of a permitted act..$^{90}$ It was established in the US case of Atari Games Corp v Nintentdo of America Inc that software decompilation is also a fair use under US copyright law ${ }^{91}$

\subsection{Copyright Effectiveness Overseas}

Keeping in mind that the team in the case study identified the US as a potential target market outside of NZ, it is important to note that the copyright laws are significantly different in the two countries. In $\mathrm{NZ}$ the word design is accepted as including definitions in the engineering sense as well as the artistic.

\footnotetext{
${ }^{86}$ Copyright Act 1994, s 80A(2) (a).

${ }^{87}$ Copyright Act 1994, s 226.

${ }^{88}$ Copyright Act 1994, s 226F(b).

${ }^{89}$ Copyright Act 1994, s 226G(1).

${ }^{90}$ Copyright Act 1994, s $226 \mathrm{E}(1)$.

${ }^{91}$ Atari Games Corp v Nintendo of America Inc. 975 F.2d 832 (Fed. Cir. 1992).
} 
Both definitions of the word include configurations of functional and useful articles, which are recognised as being created for their own sake, distinct from the art. ${ }^{92}$

US copyright law is also broad ranging and indeed copyright protection in the US can be obtained for a large variety of designs. However copyright is almost always unobtainable in the US when it comes to industrial designs. ${ }^{93}$ This is because US copyright law excludes from protection designs that are used for useful articles and that are not identifiable separately from, or cannot exist independently of, the utilitarian aspects as a work of art. ${ }^{94}$

It was stated in the US case Brandir International Inc v Cascade Pacific Lumber $\mathrm{CO}^{95}$ that a design will be conceptually separable from the utilitarian aspects of the work, where it can be successfully shown that the elements of the design reflect the designer's artistic judgement, which was exercised independently of any functional considerations. ${ }^{96}$ The toy in the case study meets the definition of a useful article and although not impossible, it will be very hard to establish that any elements in the design reflected the designer's artistic judgment independently of functional considerations. This is because the elements of the toy have been designed in a particular way to reflect a practical purpose. Therefore it is very likely that it will be necessary to obtain a US design patent, if the team do decide to enter the US market.

\subsection{Copyright Limitations}

NZ copyright protection for industrial products is not reciprocal because few other countries provide for industrial design protection under copyright. ${ }^{97}$ 'Interviewee B' explained that something more than copyright may be preferable in some overseas markets. They said: "even if we did not have copyright, the risk of copying our products is so low that we do not think it is worth worrying about in the countries where we have a presence. However there other markets out there, where we would probably want more serious protection. "

\footnotetext{
${ }^{92}$ Caenegem, above $\mathrm{n} 31$, at 130.

${ }^{93}$ Lena Schickl "Protection of industrial designs in the US and in the EU: Different concepts or different labels?" (LLM Dissertation, University of Washington, 2012) at 16.

${ }^{94}$ Copyright Act 17 U.S.C. § 101.

${ }^{95}$ Brandir International Inc. v Cascade Pacific Lumber Co 834 F 2d 1142 (2d Cir 1987).

96 Ibid, at 1145.

97 Sumpter, above n 55, at 284.
} 
Copyright is also subject to evidentiary difficulties. In particular, issues around ownership often arise. Whereas with registered designs this is not an issue because ownership is evident from the register. ${ }^{98}$ The certificate of registrations signals not only who the owner is, but it also clearly defines the protection parameters of the design. ${ }^{99}$ Another limitation of copyright is the fact that access to the work must be proved. There is no such requirement for registered designs. ${ }^{100}$

\subsection{Copyright Summary}

Copyright protection is automatically acquired in NZ upon the creation of an original work. It effectively protects the particular expression of an idea and in NZ this extends to industrial designs including the three dimensional representations of the design, made for the purposes of sale and hire. Copyright does not protect the functional elements of a work, as that would mean encompassing the idea itself within the ambit of protection. NZ is one of few countries that provides protection for industrially applied artistic works under copyright law. Therefore companies that wish to acquire protection for industrial designs overseas, should do so by registering the design.

In relation to the toy in the case study it is likely that copyright protection has been automatically acquired in NZ. However the same protection is unavailable under US copyright law, which does not permit protection for industrially applied designs.

\section{Layout Designs}

The Layout Designs Act 1994 provides a protection mode similar to copyright for owners of integrated circuits and layout designs. Just as is the case with copyright these layout designs and integrated circuits do not have to be novel but they must be original. Moreover this mode of protection is also acquired automatically. ${ }^{101}$ The Act specifies that in order for the design to be original it must have been produced as the result of an intellectual effort by the maker. The layout design cannot have been commonplace at the time it was made. In the case of a combination of elements and interconnections that are commonplace as a whole, the maker will not have exerted intellectual effort and thus the work would be unoriginal. ${ }^{102}$

\footnotetext{
${ }^{98}$ Caenegem, above $\mathrm{n} 31$, at 162.

${ }^{99}$ Sumpter, above $\mathrm{n} 55$, at 283.

${ }^{100}$ Caenegem, above n 31, at 162.

${ }^{101}$ Susy Frankel Intellectual Property in New Zealand (LexisNexis, Wellington, 2011) at 812.

102 Layout Designs Act 1994, s 6.
} 
For the purposes of the case study this is likely to be an automatically acquired protection mode as the toy has integrated circuits within its internal mechanisms. These circuits are laid out in a manner that is unlikely to be deemed commonplace as the functions which they dictate appear to be original.

\subsection{Layout Design Benefits}

The Layout Designs Act 1994 (the LDA) states that an integrated circuit means a circuit that is either in its final or intermediate form, in which there are elements, at least one of which must be active. Furthermore it must have some or all of its interconnections integrally formed in or on a piece of material and it must be intended to perform an electronic function. A layout design is the three dimensional disposition of the elements, however expressed, with at least one being an active element. It must have some or all of the interconnections of an integrated circuit including a three dimensional disposition which is prepared for an integrated circuit and is intended for manufacture. ${ }^{103}$

From this definition it is evident that this mode provides for protection of functional elements as far as integrated circuits are concerned. As such the level of protection exceeds that available under copyright and it begins to resemble patent law. However there are also some very substantial differences between patents and layout designs.

\subsection{Layout Design Limitations}

Even though this mode of protection appears to resemble patent law to the extent that it can also be used to protect functional elements, it is nonetheless a substantially weaker mode of protection.

This becomes very apparent when one examines some of the exceptions to infringement listed in the LDA. One example is the exception that a person will not be in breach of the owner's exclusive right to commercial exploitation if at the time of acquiring the unauthorised integrated circuit they were unaware and could not have been reasonably expected to know that the integrated circuit was unauthorised. ${ }^{104}$ In contrast patent law allows for no such excuses. Furthermore patent law prohibits reverse engineering whereas under the LDA reverse engineering is listed as a fair use right. ${ }^{105}$

\footnotetext{
103 Layout Designs Act 1994, s 2(1).

${ }^{104}$ Layout Designs Act 1994, s 15(1).

105 Layout Designs Act 1994, s 18.
} 


\subsection{Layout Design Effectiveness Overseas}

The exclusive rights provided for the owner by virtue of the LDA are: the right to exploit the layout design commercially in NZ and other eligible countries, as well as the exclusive right to copy the design layout and make an integrated circuit in accordance with that layout design. ${ }^{106}$

Eligible countries are those that are party to the Agreement on Trade-Related Aspects of Intellectual Property Rights (TRIPS agreement). ${ }^{107}$ For the purposes of the case study it is important to note that the US is an eligible country. The same protection can be acquired in the US under the Semiconductor Chip Protection Act $1984 .^{108}$

\subsection{Layout Design Summary}

Protection for integrated circuits and layout designs is acquired automatically in NZ and other eligible countries that are party to the TRIPS Agreement, provided that the originality threshold is met. The LDA provides protection for functional elements so far as integrated circuits are concerned and to that extent resembles patent law. However the owner is not provided with a monopoly, as would be the case with a patent. Instead what is provided for by the Act are a number of exclusive rights, much like what one gets under copyright protection.

The toy in the case study is likely to have automatically acquired protection for its integrated circuits and layout design and this mode of protection is also provided for in the US.

\section{Trade Marks}

Prior public disclosure is a concept that is irrelevant to trade mark protection. A trade mark is any sign capable of being represented graphically, which distinguishes the goods or services of one person from those of another person. ${ }^{109} \mathrm{~A}$ trade mark application registration is completed together with a list specifying the goods or services to which the mark is going to applied in trade. Nowadays a trade mark may extend beyond mere logos and distinctive words. It may also include shapes, sounds, colours and potentially even smells. ${ }^{110}$

\footnotetext{
106 Layout Designs Act 1994, s 13.

${ }^{107}$ Frankel, above n 99, at 812.

108 Ibid.

109 Trade Marks Act 2002, s 5.

110 Sumpter, above n 55, at 142.
} 


\subsection{Trade Mark Effectiveness Overseas}

A trade mark is a long standing and worldwide accepted mode of IP protection. In recognition of this fact, most countries around the world are members of the Madrid Protocol, which allows applicants to file a single application for registration designating at once all the countries where protection is sought. Of course these countries must also be members of the Madrid Protocol. NZ joined the Madrid Protocol in 2011. ${ }^{111}$ Therefore when an application is filed for registration of a trade mark for the toy, the US, being a potential target market outside of NZ can be designated as a country where protection is also sought.

\subsection{Trade Mark Benefits}

A clear benefit of having a registered trade mark is that it can be easily dealt with in modern commercial transaction. It can be licensed, sold or transferred to another owner efficiently and with ease. ${ }^{112}$ Moreover registered trade mark infringement is easy to prove. ${ }^{113}$ Another obvious benefit of a registered trade mark is that in contrast with all other forms of IP protection, this mode does not have a time limit. Trade mark protection is indefinite, provided that the mark continues to be used and renewal fees are paid. ${ }^{114}$ However there are a number of grounds upon which an application for a registered trade mark may be refused.

\subsection{Trade Mark Opposition}

Prior to a trade mark being registered, the mark is advertised as an accepted application in "the Patent Office Journal". This advertisement provides third parties with an opportunity to oppose the registration. This opposition can be conducted by anyone, so long as it is done within three months of the Patent Office Journal publication. ${ }^{115}$

\subsubsection{Distinctiveness Threshold}

A common ground of opposition is that the mark is not sufficiently distinctive. Only distinctive signs are capable of being registered as a trade mark. Marks which describe the nature of the goods or services that the trader is concerned in cannot be registered. Often a sign's inherent distinctiveness will be dependent upon which goods and or services it seeks registration in. Words or word

\footnotetext{
111 Ibid, at 144.

${ }^{112}$ Arthur and Sumpter, n 33, at 7.

113 Ibid, at 12.

${ }^{114}$ Sumpter, above n 55, at 142.

${ }^{115}$ Arthur and Sumpter, n 33, at 10.
} 
combinations which serve to designate the kind, quality, quantity, intended purpose, value or the like of goods and services for which they are used are insufficiently distinctive for registration. ${ }^{116}$ However there is an exception. Like colours, shapes and smells, words too can sometimes be descriptive and still be registered if the trader can show sufficient evidence, which demonstrates that the public understands the word or phrase to distinguish them as the particular trader. ${ }^{117}$ However in order to satisfy this requirement, the trader must provide substantial proof that shows the public has actually grown to associate the descriptive mark with that trader as its particular source. It would have to be shown that a significant portion of customers in the relevant market recognise that the descriptive mark is a badge of origin. ${ }^{118}$

One proposed name for the toy in the case study stems from the word "Autistic". Therefore it is arguable that the name of the toy is insufficiently distinctive because it is describing the nature of the good. It is also arguable that the publicity over the internet, which impedes on the ability to get a patent and registered design, has generated reputation in the mark. However this limited exposure cannot by any means be regarded as having generated sufficient reputation to the extent that the public could be shown to associate this particular mark with the toy. Although the name and label have been published on the internet, the toy is not being traded and therefore there are no customers at the present time that can be shown to make the association.

\subsubsection{Offensive Marks}

The fact that the name is potentially offensive to the New Zealand community is another potential ground of opposition which is directly relevant to the toy in the case study. ${ }^{119}$ There is a risk that the name will be offensive to some people, particularly those in the autism community. Even though there is no definition of the word "offend" in the Trade Marks Act 2002, the Commissioner of Trade Marks has stated that it would be sufficient to refuse registration where a significant portion of the NZ community would find the word offensive, shocking or improper. ${ }^{120}$ Therefore, if the autism community at which the toy is targeted is considered to be a significant portion of the community and is offended by the name of the toy, this fact may meet the threshold of being "offensive".

\footnotetext{
116 Trade Marks Act 2002, s 18(1)(c).

117 Trade Marks Act 2002, s 18(2).

${ }^{118}$ Sumpter, above n 55, at 158.

119 Trade Marks Act 2002, s 17(1)(c).

120 Trade mark application by Red Bull GMbH [2001] NZIPOTM 33.
} 


\subsection{Trade Mark Limitations}

Aside from some of the difficulties that may potentially be encountered when trying to register the mark, trade mark protection also has some practical limitations. 'Interviewee C' was of the opinion that: "trade marks can be hellishly expensive and yet ineffective when people try to trade mark every single little thing in every country. That is a recipe for disaster." This opinion reflects the fact that damages are notoriously difficult to calculate in trade mark infringement proceedings because it is very difficult to quantify the amount of trade that had been diverted as a result of the infringing mark. ${ }^{121}$ For that very reason most companies trade mark few things outside the company name and logo. 'Interviewee D' confirmed this approach: "we focus on protecting our name and logo."

\subsection{Trade Mark Summary}

Trade marks are important in any business venture. They are the badge of origin of any good or service. Furthermore they are the embodiment of a company's reputation. As such, trade marks unlike all other forms of IP protection have no expiry date. The Madrid Protocol is recognition of trade mark importance on an international scale. As a result of the Protocol one can register a trade mark in multiple countries under one application.

A trade mark is a mode of protection that should be acquired for the toy in the case study. However, it is important that team choose a mark that is identifiable with their vision and aspirations. The current name is in danger of being deemed insufficiently distinctive. Furthermore it is potentially offensive. The team should choose their mark wisely and with caution, because it would be a big mistake to offend the target market, even if the mark can technically be registered.

\section{Alternative Modes of Protection}

\subsection{Passing Off}

Passing off is an alternative method for protecting a trade mark. The tort action is an example of how one can protect their IP without relying on IP law. One will have to rely on passing off in the event that their mark is not registered. However, proof of a significant reputation is required in order to establish this tort.

Reputation is established where it is shown that consumers have been conditioned into associating a mark with the goods or service of a particular source. Such conditioning occurs when the consumer is significantly exposed to the mark over time through promotion and sales. ${ }^{122}$ For example 'Interviewee

\footnotetext{
${ }^{121}$ Arthur and Sumpter, above n 33, at 15.

${ }^{122}$ Sumpter, above n 55, at 194.
} 
$\mathrm{B}^{\prime}$ has a reputation for manufacturing virtually unbreakable products. The authorised representative from the company had this to say on the subject: "our products are sort of like an airline and an airline is only as good as its crash. If it has not had a crash, it must be a good airline. So with our products, if they do not work we will have to shut down shop overnight because no one would buy our gear." What the interviewee is essentially describing here, is the goodwill of their company. Goodwill is perhaps best described as the benefit and advantage of a good name, reputation and connection of a business. That is the attractive force which brings in custom. ${ }^{123}$

An example of a situation where passing off was established in NZ is the Tot Toys Ltd v Mitchell ${ }^{124}$ case. In this case the plaintiff successfully established that the defendant had passed off because it was quite clear that over the years the toy they had produced became famous and widely recognised in the NZ market. Therefore any similar toy regardless of the name was associated with the plaintiff, by the consumer.

For the purposes of the case study, passing of is not really a viable option as it concerns a start-up venture. Passing off requires significant consumer exposure, which essentially means that a substantial amount of time must pass before the necessary goodwill can be generated in the unregistered mark.

\subsection{Fair Trading Act 1986}

The Fair Trading Act 1986 is an additional trade mark protection method. The provision which is most prominent and relevant to trade marks is section 9. It reads: "No person shall in trade engage in conduct that is misleading or deceptive or is likely to mislead or deceive".

In contrast to passing off, a trader is able to enforce section 9 against a competitor without having to prove their own goodwill or reputation. This is because the section is concerned with consumer protection. Therefore if the consumer is being misled or deceived, that will be enough for enforcement of the section. ${ }^{125}$ However this is only a theoretical distinction because in practice evidence of reputation is nonetheless required in a Fair Trading Act action, if there is an alleged confusion of names. ${ }^{126}$

\footnotetext{
${ }^{123}$ IR Commmrs v Muller \& Co's Margarine Itd [1901] AC 217 (HL) at 223-224.

${ }^{124}$ Tot Toys Ltd v Mitchell (1992) 4 NZBLC 102, 797; [1993] 1 NZLR 325.

${ }^{125}$ Sumpter, above n 55, at 200.

$126 \mathrm{Ibid}$, at 201.
} 
For the purposes of the case study it is important to note that the Fair Trading Act 1986 may be used once the toy enters the NZ market, in the event that the team's chosen trade mark is infringed. However the Fair Trading Act 1986 is a NZ statute and therefore cannot be relied upon to protect the trade mark in overseas markets.

\subsection{Trade Secrets}

Trade secrets are another alternative method for protecting a company's IP. Although it is often grouped together with other modes of IP protection it is not technically IP law because unlike the others it is not a property right. ${ }^{127}$ Trade secrets are protectable under the legal doctrine of "breach of confidence". A trade secret is confidential information that is of commercial value, such as a particular manufacturing process. ${ }^{128}$

It was mentioned in the patents section of this paper that many entrepreneurs involved in start-up companies are often very nervous about novel ideas leaking into the public domain and as a result spend a lot of money on IP protection. Certain companies such as 'Interviewee A', choose to rely on trade secrets rather than pay fees for IP protection. Trade secrets are a good cost saver, however they are not entirely cost free as expenses have to be incurred to keep the information secret. For example, the cost of contracts which impose non-disclosure obligations on involved parties. ${ }^{129}$

In reality few companies can successfully keep their trade know-how a secret. This is due to the fact that information, once placed in the open market is no longer confidential. For many companies this means that regardless of what confidentiality measures are taken, all the necessary information can be acquired by competitors through the process of reverse engineering. It is important to note the distinguishing feature of 'Interviewee A's' firm: "our IP is in our detailed technical designs and people's knowledge." Their trade secrets are therefore not exposed when they enter the marketplace, as the confidential information is not contained within their products.

The same cannot be said for the team in the case study because the IP of the toy being developed is in many of its functional features. Therefore the toy will certainly become vulnerable to reverse engineering once it enters the open market.

\footnotetext{
127 Ibid, at 308.

128 “How are Trade Secrets Protected?” World Intellectual Property Organisation <www.wipo.int>.

129 Howard Eisenberg "Patent Law You Can Use: Patents vs. Trade Secrets" (2000) Yale University Office of Cooperative Research<www.yale.edu>.
} 


\subsection{Alternative Modes of Protection Summary}

There are alternative methods of protection available outside IP law that are sometimes relied on by businesses. Companies may rely on the tort action of passing off once they have acquired a significant reputation in a mark. Significant reputation is acquired once consumers associate the mark with the particular trader. The Fair Trading Act 1986 is another alternative method for protecting an unregistered trade mark, once a business begins to trade in the marketplace. However the Fair Trading Act 1986 is a NZ statute, and thus only applies when infringement occurs in the domestic market. A trade secret is another way to protect IP, without relying on IP law. However not many companies can keep confidential information a secret once they enter the market place. In reality trade secrets can only stay as such when a product is so complex that competitors are unable to make sense of it when they attempt to reverse engineer it. The much more common scenario is where IP is not within the product at all, but rather in something like the manufacturing process or intellectual capital.

\section{Conclusion}

In summary it is important to recall the earlier observation identified in this paper; that although practice is sometimes different to what is prescribed by the legal system, in the majority of cases the law is fundamental to the way things are done in the commercial world. When it comes to business the legal system has such a substantial effect on the workings of the economic system that it can essentially be said to shape and control it.

The letter of the law is also unavoidable when it comes to product safety standards as these are legal obligations. It is therefore absolutely vital that the toy in the case study complies with the product safety standards, which apply to children's toys.

However there are some businesses that act and choose strategies, which are not so reliant on the law. For example, some companies choose not to acquire legal protection measures for their IP, outside those that are automatically acquirable. These types of companies are not common. Usually a company is only able to do this, when their strategy involves consistently updating their products in order to stay on top of the competition. Another strategy is to keep the IP secret, but this is only sufficient where the IP can stay confidential, despite the product entering the market. In most cases, the legal modes of IP protection are absolutely necessary because the company's products are not that complex and can be reverse engineered, once in the hands of competitors. Furthermore, most companies do not have the funds or resources to consistently innovate and update their products in order to maintain their competitive advantage. 
It is therefore important that the team in the case study acquire patent protection for any of the functional features which have been developed since the public disclosure, which prove to be truly innovative. This is because such features will certainly become vulnerable to reverse engineering once the product enters the marketplace. In regards to the design of the product, it may be worth changing it substantially in the event that product testing reveals that the children are responding particularly well to the functional features, without any real care for the design of the toy. If the design is changed substantially it can be registered in NZ and it will also make it possible to acquire a Design Patent in the US, if the team do decide to pursue that market. Registering a trade mark in a name and logo that represents the venture is also important, as it will be some time before there is significant reputation attached to any potential unregistered marks associated with the toy. 


\section{Bibliography}

\section{Legislation}

Commerce Act 1986.

Copyright Act 17 U.S.C.

Copyright Act 1994.

Designs Act 1953.

Fair Trading Act 1986.

Layout Designs Act 1994.

Patents Act 1953.

Patents Act 2013.

Patents Act 35 U.S.C.

Trade Marks Act 2002.

\section{Case Law}

Atari Games Corp v Nintendo of America Inc. 975 F.2d 832 (Fed. Cir. 1992).

Bonz Group (Pty) Ltd v Cooke [1994] 3 NZLR 216.

Brandir International Inc. v Cascade Pacific Lumber Co 834 F 2d 1142 (2d Cir 1987).

General Tire \& Rubber Company v Firestone Tyre \& Rubber Company Ltd [1972] RPC 457.

Henkel KGaA v Holdfast New Zealand Ltd [2007] 1 NZLR 577 (SC).

IR Commmrs v Muller \& Co's Margarine Itd [1901] AC 217 (HL).

Molecular Plant Breeding Nominees Ltd v Vialactia Bioscience (NZ) Ltd (IPONZ, Assistant Commissioner Popplewell, 12 September 2005).

Sealed Air New Zealand Limited v Machinery Developments Limited (unreported, High Court, Wellington, CIV-2003-485-2274, 25 August 2004.

Sutton v Bay Masonry Limited unreported, High Court, Tauranga CIV 2003-470-260, 28 May 2004.

Tot Toys Ltd v Mitchell (1992) 4 NZBLC 102, 797; [1993] 1 NZLR 325.

Trade mark application by Red Bull GMbH [2001] NZIPOTM 33.

UPL Group Limited v Dux Engineers Limited [1989] 3 NZLR 136. 


\section{Journal Articles}

A Dumi, Z Sinaj and M Nuhiu "Intellectual Property Rights and Economic Development" (2012) 2 Journal of Educational and Social Research 321.

Lee Epstein and Jack Knight "Building the Bridge from Both Sides of the River: Law and Society and Rational Choice" (2004) 38(2) 207.

Mark Lemley and John Duffy "Property, Intellectual Property, and Free Riding/Comment/Reply" (2005) 83 Texas Law Review 1031.

O Lee Read "Law, The Rule of Law, and Property: A foundation for the Private Market and Business Study" (2001) 38(3) American Business Law Journal 441.

Robert Ostergard "The Measurement of Intellectual Property Rights Protection" (2000) 31(2) Journal of International Business Studies 349.

Roland Kirstein "Intellectual Property: Economic and Legal Dimensions of Rights and Remedies" (2006) 89(1) European Journal of Law and Economics 90.

\section{Texts}

Guido Westkamp (eds) Emerging Issues in Intellectual Property: Trade, Technology and Market freedom (Edward Elgar, Cheltenham, 2007).

John Skinnon and John McDermott (eds) Law of Marketing in New Zealand ( $2^{\text {nd }}$ ed, Butterworhts, Wellington, 2001).

Paul Sumpter Intellectual Property Law: Principles in Practice ( $2^{\text {nd }}$ ed, $\mathrm{CCH}$ New Zealand Limited, Auckland, 2013).

Susy Frankel Intellectual Property in New Zealand (LexisNexis, Wellington, 2011).

William Caenegem Intellectual Property Law and Innovation (Cambridge University Press, New York, 2007).

\section{Internet Materials}

"Children's Toys: A Guide to Complying with the Product Safety Standard" (2009) Commerce Commission New Zealand at $1<w w w . c o m c o m . g o v t . n z>$.

Donal O'Connell "Why Intellectual Property Matters: The Growing Importance of Intellectual Property" (2013) Imperial College London <www3.imperial.ac.uk>.

"Dulux Recalls Toy Dogs after Complaint to Commerce Commission" (2012) Commerce Commission New Zealand <www.comcom.govt.nz>.

Howard Eisenberg "Patent Law You Can Use: Patents vs. Trade Secrets" (2000) Yale University Office of Cooperative Research< www.yale.edu>.

“How are Trade Secrets Protected?" World Intellectual Property Organisation <www.wipo.int>. 
"Legal Theory: Law and Society" (2013) Berkman Center for Internet and Society $<w w w . c y b e r$.law.harvard.edus.

Randal Jackson "Patents Bill Passes into Law" (2013) Computer World the Voice of IT Management $<$ www.computerworld.co.nz>.

\section{Other}

Greg Arthur and Matt Sumpter "Intellectual Property for Non-Specialists" (paper presented to New Zealand Law Society Seminar, Wellington, August 2008).

Lena Schickl "Protection of industrial designs in the US and in the EU: Different concepts or different labels?" (LLM Dissertation, University of Washington, 2012).

Wesley Cohen, Richard Nelson and John Walsh "Protecting Their Intellectual Assets: Appropriability Conditions and Why U.S. Manufacturing Firms Patent (or Not)" (NBER Working Paper No. 7552). 


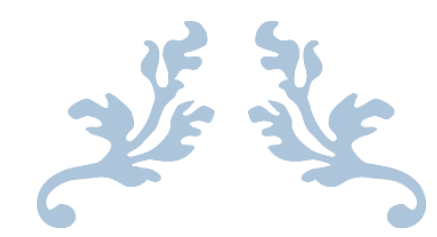

\section{PART 2: Appendix}




\section{Contents}

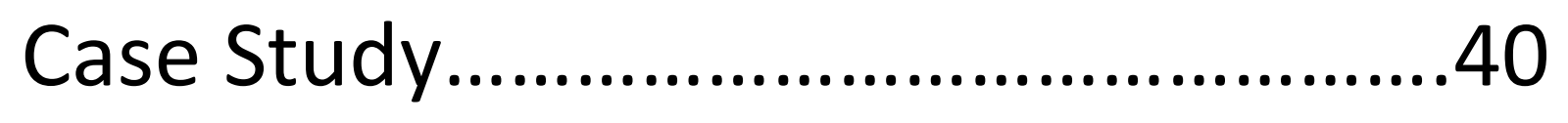

Business Plan.....................................48

Legal Strategy..................................60 


\section{Contents}

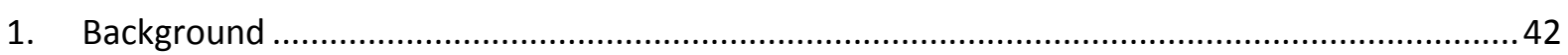

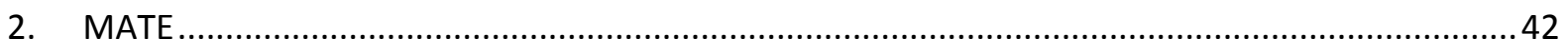

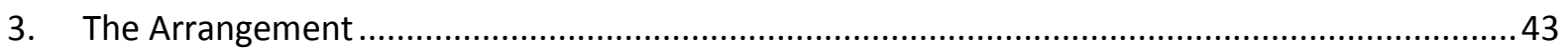

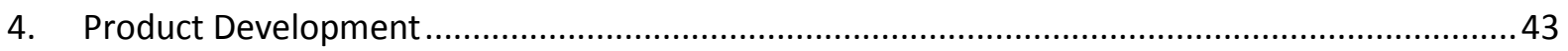

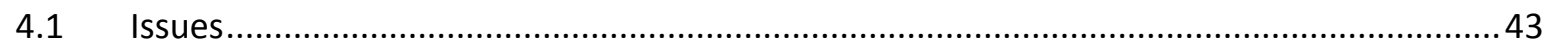

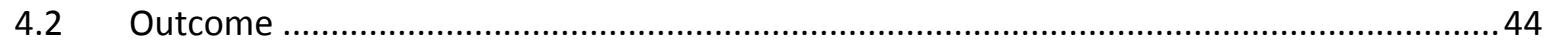

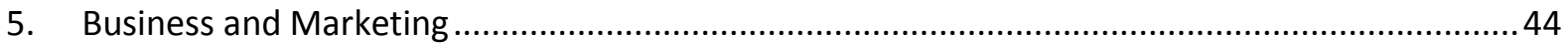

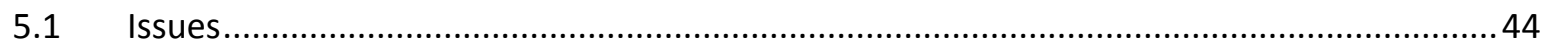

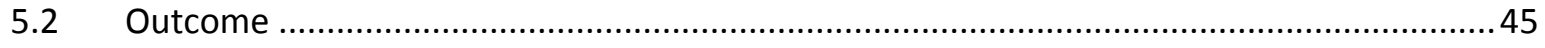

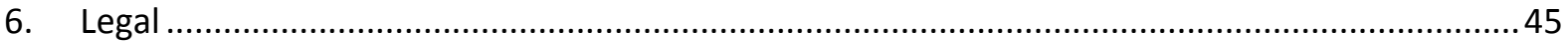

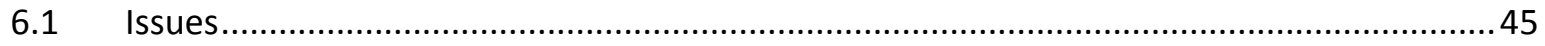

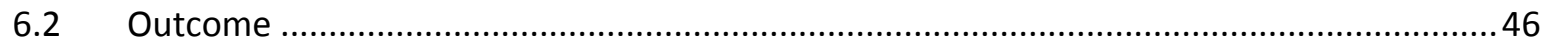

7. End of Year Progress Summary and Business Proposition.........................................................46

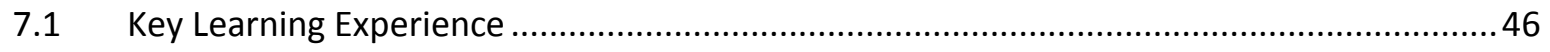

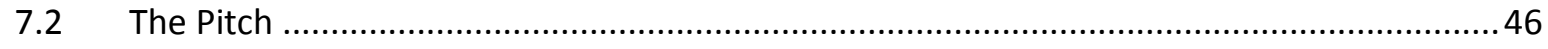

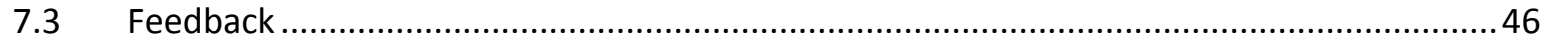

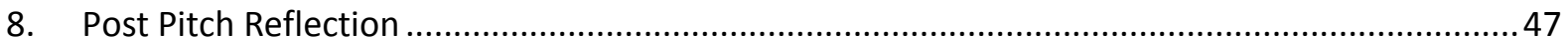




\section{Case Study}

\section{Background}

The project began in an undergraduate university course where a student (the project champion) excelled in an assignment by creating the original prototype toy.

The toy was designed for the purposes of helping children with Autism. The project champion's vision was that the toy would be a social behaviour development tool for these children. The idea was simple, but seemed to have potential and generated a lot of interest very quickly. So much interest in fact, that Victoria University offered the project champion the opportunity to take the Masters in Psychology programme. One of the core things she would do in this programme is test the effectiveness of her invention by running some trials with a number of autistic children.

The project champion became understandably excited about her invention and the fantastic opportunity offered to her by the university and so she went online. She began to post blogs about her idea and put up photos and videos of the prototype. This quickly generated even more interest, particularly from the Autism community. She then displayed the prototype at a public exhibition in order to confirm the potential of the invention.

With all of this attention, it soon became apparent that the toy could have some real commercial potential. This meant that the prototype was potentially worth developing into a product. The project champion approached a Masters level electric engineering student to help her develop the prototype. This student has been involved in the project ever since.

However aside from product development, the project required a business and marketing plan. The project champion also later realised that she had potentially made a mistake from a legal standpoint by posting pictures and information of her invention online and by taking the prototype to an exhibition, prior to acquiring any type of legal protection. The project champion needed help in these areas of the project. Coincidently she then heard about the Masters of Advanced Technology Enterprise (MATE) programme.

\section{MATE}

The MATE programme is a course which was run for the first time in 2013 , by Victoria University. The programme is available to post graduate students from different backgrounds of study. These students are required to form teams around a project to which they can contribute value. 
The project champion proposed the toy as a potential project. She prepared a short presentation in which she pitched the potential of her idea and asked for assistance.

Three students agreed to form a team to take on the project. One of these students was Anna Samoylova. Anna is an international business and marketing major and as such was the ideal candidate to take charge in relation to the business and marketing work. Vlad Samoylov is a law major, who naturally took on the legal aspects of the project. The final team member was Tiara Wan who was a bio-tech major. Tiara chose to be responsible for product development.

\section{The Arrangement}

When the project was first pitched to the MATE class, there was unanimous concern expressed by all students in relation to the lack of testing. The idea behind the prototype appeared innovative, but there was no proof that the toy would generate the desired response from the autistic children. Therefore, the project champion was asked whether it would be possible to do some initial testing with a small number of children at an earlier stage in the year. This initial testing would identify what features were successful and which features needed further developing. This information would help identify the minimum marketable product.

The project champion agreed to conduct the testing earlier, in order to establish what the minimum marketable product was and this agreement was the basis for the formation of the team.

\section{Product Development}

The toy has come a long way since the initial public disclosure. The product development team working on the project have produced a number of new features which did not exist at the time of the disclosure. However the success rate of these features is still unknown despite the initial agreement, as testing with the children has only recently commenced.

\subsection{Issues}

The product development team were unable to begin testing the product until a much later stage in the year as they encountered great difficulty finding test subjects, given the sensitive nature of the project.

The project champion did not want Tiara being involved in work relating to the product's development because it was an area of work that she chose to remain entirely in charge of. The project champion had already acquired assistance in this area of the project prior to addressing the MATE students. Therefore she now only required assistance in work relating to the business and legal aspects of the project. 


\subsection{Outcome}

The toy is almost entirely complete in the sense that most features which were originally planned to be incorporated into the product, are now in place. However, due to the fact that testing was delayed, the success potential of the product at the current stage of development is still unknown.

The project champion did not want Tiara being involved in product development and testing. After some time, Tiara decided to resign from the project entirely.

\section{Business and Marketing}

Anna took charge in relation to the business and marketing aspects of the project. She began by conducting some thorough market research. After having completed her literature review, she wrote up question guides and surveys, which would be used in a series of interviews with therapists and parents of children with autism. She submitted these to the Victoria University Human Ethics Committee (VUHEC) for approval.

Anna was also prepared to go out and look for financial assistance for the purposes of expanding the product development team. She drew up a business plan and made arrangements to meet with potential investors.

\subsection{Issues}

The project champion was concerned that the interviews with the therapists and parents could be potentially detrimental to the project, if conducted by someone who was not well versed in psychology and who had limited knowledge about autism. Anna had conducted research on autism, but the project champion was nonetheless concerned that she would potentially offend the highly sensitive market by conducting these interviews. In fact due to a slight misunderstanding, the project champion believed that Anna had already conducted some interviews and that this had contributed to the difficulty in finding willing test subjects. Of course, Anna did no such thing as she was still awaiting ethical approval and confirmation from the project champion herself.

Once the misunderstanding became resolved, the project champion informed Anna that she would take the surveys and interview guides and conduct the interviews herself at a later stage, as this was a very sensitive market and since she had more knowledge about autism.

The project champion did not allow Anna to approach investors because she felt that the product development team had developed some new intellectual property, which she did not want to disclose in exchange for financial assistance. 


\subsection{Outcome}

Due to the very small size of the product development team, the toy took a long time to develop. Also the delay in product testing means that the toy's business potential is still unknown. Therefore the business plan accommodates in the best way possible, for a number of potential outcomes.

\section{Legal}

The primary task that lay before Vlad was to identify the legal ramifications of the prior public disclosure. After conducting an extensive literature review, Vlad was able to identify the Intellectual Property (IP) protection modes that were adversely affected by the disclosure. He then looked for exceptions and identified what had to be done in order to once again have the availability of these modes of protection.

Vlad then identified and advised the project team, including the project champion, about the effectiveness of the modes of protection that were available despite prior public disclosure. He also identified the protection modes, which the toy had potentially automatically acquired and advised the team about the benefits and limitations in relation to each of these.

At a later stage in the year, after examining Anna's market research, the team including the project champion agreed that a potential target market outside of New Zealand (NZ) could be the United States of America (US). Vlad then set out to examine US legislation and case law, in order to identify the US requirements for acquiring IP protection. He also identified some of the key differences between US and NZ protection measures. At around this time, Vlad received approval from the VUHEC to interview local manufacturing firms that sell their products overseas as well in NZ. These interviews provided him with insight into IP protection measures that are taken by companies when operating in foreign markets.

Aside from investigating into IP protection, Vlad also examined product safety standards. He was able to identify the standards that were applicable to the toy and advised the team as to what had to be done in order to ensure that the standards were complied with.

\subsection{Issues}

Due to the product development team having not yet completed testing the newly developed features, it is still unknown whether they are generating the desired response from the children and are thus worthy of legal protection. 


\subsection{Outcome}

Existing legal protection has been identified and a legal strategy has been produced for the foreseeable future. This is a strategy that can be implemented once testing is complete.

\section{End of Year Progress Summary and Business Proposition}

After several months the project team were asked to prepare a presentation which would summarise their progress and identify their key learning experiences. The team also chose to pitch a business proposition at the end of the presentation. The presentation was held before a panel of academics and experienced entrepreneurs.

\subsection{Key Learning Experience}

The key learning experience for the project team was experiencing the difficulty of finding willing test subjects when the product being tested strives to achieve a therapeutic benefit. In this case the toy aims at improving the social behaviours of children with autism. The difficulty primarily stems from parent's reluctance to test such a product on an autistic child. Parents are generally unwilling to subject their child to such testing until the product has gone through all the necessary ethical approvals and usually not until the testing is backed by therapists, or is conducted within the confines of official therapy sessions.

\subsection{The Pitch}

The team made a proposition to the project champion, recommending taking a shift in business strategy from the main vision in the short term in order to focus on developing a minimum marketable product. This proposition had been made to the project champion early on in the project, but after several months of market research the team were now even more confident that they had identified demand in the market for much simpler variants of the toy. The key difference is that these variants would not promise to produce any kind of therapeutic benefit, making it substantially easier to find test subjects and thus allowing the team to identify a minimum marketable product much sooner. The culmination of the necessary approvals and expert backing for the initially envisioned toy could continue to be acquired for the long run, while simpler products could be developed and marketed in the near future. These simpler products would in turn provide the much needed finance for further development of the envisioned toy.

\subsection{Feedback}

The panel of academics and experienced entrepreneurs provided feedback on the team's proposition to the project champion. The entire panel acknowledged that the clash between the team's proposition and the project champion's set vision for the product can be a serious obstacle in a 
business venture. They said that there comes a point in any business venture where it is up to each individual member to decide whether to agree with the vision and pursue it, or walk away from the project all together. The unanimous opinion of the panel was that it is probably worth pursuing the project vision despite the extensive delays because the toy has the potential to be such a good product. They said that the project addresses such a big societal issue that it is worth taking the long and tedious journey, even if it means only coming up with a very small part of the solution. Furthermore they explained that the time and effort that goes into all the testing makes it that much harder for any potential competitors to emulate the product.

\section{Post Pitch Reflection}

Since the presentation, the team have taken on board the feedback from the panel and have decided not to take the shift in business strategy for the sake of developing variant products, as these may have the effect of taking away from the reputation that they are trying to establish. The team is striving to become a business that produces products which are proven to be successful therapeutic tools. In order to ensure that the toy lives up to its full potential all the necessary testing is currently being conducted. 


\section{Contents}

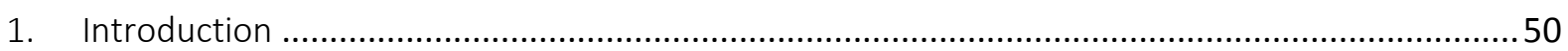

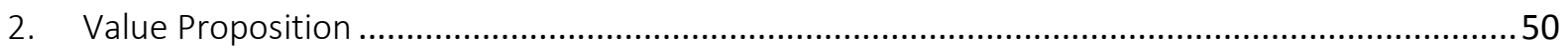

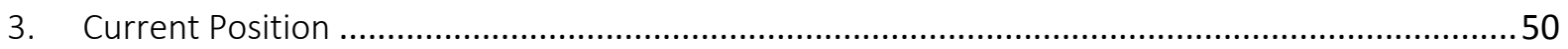

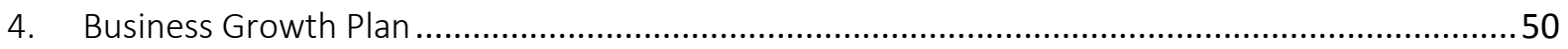

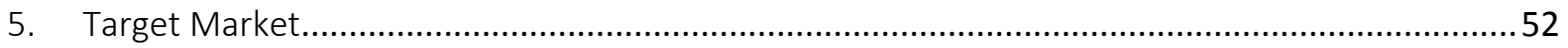

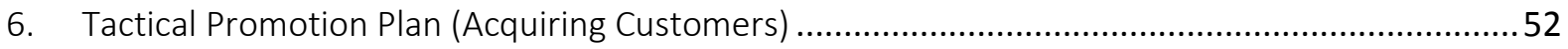

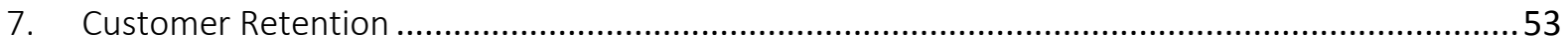

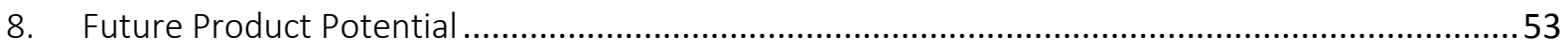

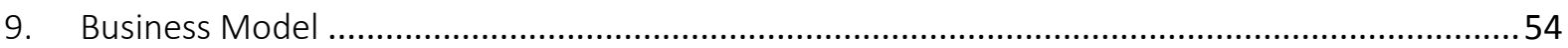

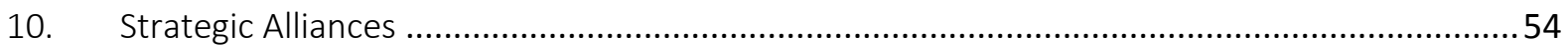

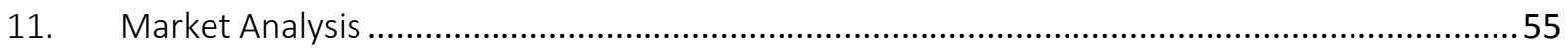

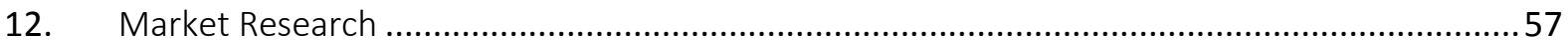

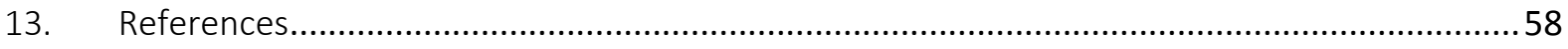




\section{Business Plan}

\section{Introduction}

The product is an interactive toy which is being designed to assist in teaching children with autism positive social behaviour. Our research enabled us to identify a number of market segments that were suitable for the toy. We also found two additional problems in the market that the toy could address:

1) Lack of respite care for autism.

2) Children with autism find it hard to transition from home to school.

\section{Value Proposition}

The vision for the completed toy is that it will be a successful social behaviour development tool for children with autism.

\section{Current Position}

Currently we are focusing on a number of tasks which include:

- Conducting testing with a selection of children who have Autism.

- Searching for potential angel investors in New Zealand.

- Perfecting the toy's functional features.

- Finalising the business proposition for our desired partners.

\section{Business Growth Plan}

We are lacking essential resources to set up shop by ourselves such as funding and human capital. The New Zealand autism market is not large enough for us to scale. One in one hundred people in New Zealand have autism (Autism New Zealand, 2013). Therefore we need to look into entering the international market. 


\section{The US market is appealing for the following reasons:}

\section{Autism statistics in the US:}

In a 2009 study it was recorded that one in eighty eight children had autism in the US. The latest statistic from the US disease control and prevention tells us that in the year 2013 on average around one in fifty children have autism in the US (Mercola, 2013). Health officials have concluded that the substantial rise is due to improvements in screening and diagnosis (Autism in the US, 2013).

\section{Economic environment analysis}

- Although Applied Behaviour Analysis (ABA) therapy is highly demanded by parents with autistic children, there are a few challenges. Therapists are expensive, they charge around $\$ 50-\$ 60$ per hour on average. Most public schools do not offer ABA therapy and most insurance companies do not cover ABA therapy as they consider it too experimental. (How much is aba therapy, 2012). As a result many parents of children with autism learn how to practice $A B A$ therapy. A parent can learn the basics of $A B A$ by themselves via online tutorials or by doing a small number of workshops. Parents are not experienced therapist and so they are always looking for tools that can help assist them with ABA therapy.

\section{$\underline{\text { Sociocultural environment }}$}

- The New Zealand ABA market is not big enough for the purposes of a sustainable business. This is due to the fact that many New Zealand parents and even therapist seem to view ABA in a negative light. This view is probably reflective of the old ABA practises, which were very strict. On the other hand, the US has a huge ABA therapy market. ABA therapy is one of the most common and successful therapies for children with autism (Newman, Hammond, 2005).

- Internationally, many parents are suspicious of robotic toys and doubt their ability to assist in teaching a child with disabilities. However some countries are more accepting of robotic toys due to their particular culture. According to Hofstede's culture dimensions, the US is ranked low in uncertainty avoidance which means the US is relatively open to trying new technologies. (Hofstede's cultural dimensions, 2013).

\section{Technological environment:}

- The US is ranked number one in the world in regards to robotic companies and research. It also has the largest national robot market. (World robots, 2013). 


\section{Region for initial focus:}

As we do not have the resource to distribute nationwide immediately, we need to focus on a specific area in the US where we can establish a brand image and generate revenue for further growth and awareness. ABA therapy is not covered by insurance in most US states, therefore we plan to target California. The governor of California Jerry Brown has signed senate bill 126, which extends the benefits of the California autism insurance mandate through till January 1, 2017. (Autism insurance mandate 2013).

\section{Target Market}

We have identified a number of potential market segments. Below is a list of these segments and an explanation of how the toy fits into each segment.

\section{1) ABA Therapists:}

There are a lack of tools which assist ABA therapist in teaching children with autism positive social behaviour. This toy is aimed at assisting therapists in therapy sessions.

\section{2) Parents}

$A B A$ therapy is very expensive. Therefore the more affordable option for many parents of children with Autism is to learn ABA themselves and then practice it in their own home. The toy is aimed at assisting the parents.

\section{3) Education}

Teachers often witness the difficulty that students with autism display when interacting with their peers. Regular methods of teaching children positive social behaviours are often inappropriate for autistic children. Therefore teachers often struggle to teach children with autism, how to appropriately interact with their classmates. The toy is aimed at assisting teachers in teaching autistic children the difference between socially positive and negative behaviour.

\section{Tactical Promotion Plan (Acquiring Customers)}

- Building a strong reputation within the autism community. A majority of parents rely on approvals and recommendations of therapists, when purchasing products that address autism. 
- Our market research has revealed that parents value customisation features in toys because every autistic child has their specific preferences. Parents will be able to customise the toy's features on an interactive website.

- We plan to get our product tested by two rating websites, which our target customers use to find suitable toys for children with autism:

1) www.ableplay.org: provides information on toys for children with special needs, including autism. All products are evaluated by the 'National Lekotek Center'.

2) www.parents-choice.org: the parents' choice award seals are internationally recognized and respected icons of quality.

- Our choice to target California is also part of a promotional plan. Many rich and famous people are located in this region who have children with autism (Buchen, 2011). If we are able to get approval from this audience, we could later use celebrities as ambassadors for the toy.

\section{Customer Retention}

- Taking a sensitive approach in a sensitive market. We need to take the time to prepare before approaching the market. We must always remain respectful and ensure that we conduct ourselves in a non-offensive manner. This helps build an overall caring image.

- Part of creating a caring brand image is making customers feel important (Campling, 2008). We want to stay in touch with our customers and hear about their progress. Customers will be able to post their experiences on an interactive website.

- Each child is unique therefore a lot of emphasis will be put into investigating and addressing customisation recommendations.

- The interactive website will have a blog section, where anyone can share the latest facts, research and interesting articles about autism.

\section{Future Product Potential}

- Our overall aim is to become a sustainable business which provides tools for various therapy sessions. The current toy is targeted at ABA therapy. Future products will target cognitive behavioural therapy, occupational therapy and speech therapy.

- We plan to integrate software into the toy. For each toy purchased, the software setting will depend on a child's age and autism type. As the child grows or progresses, parents can purchase software upgrades. 


\section{Business Model}

- Direct sales of toy.

- External material covering the outer shell of the toy will also be sold individually (different textures/ colours).

- Software

The above items will be purchasable either via our website or through online distributers such as 'PlayAbility'. Software upgrades will be downloadable off our website.

\section{Strategic Alliances}

\section{Partnership with 'Interbots'}

Creating a joint venture with a start-up rather than an established company would give us more leverage in terms of control and share allocation. (Access your options for growth, 2013). Our aim is to partner with a start-up called Interbots, who specialise in creating interactive toys. They are the creators of Popchilla, our main competitor.

Partnering with 'Interbots' would give us the following advantages:

- We are lacking the technological skills to produce a sound sensor for the toy. Interbots are experienced in creating sound sensor technology for robots.

- Interbots have experience and connections in the US autism market. They are partners with the Barber National Institute who are currently researching the effectiveness of using robots in clinical therapy with autistic children. Popchilla is already being used in trials for this research. Perhaps partnering with Interbots, would interest the Barber National Institute in using our toy in these trials as well. This would help validate our technology. The Barber National Institute is well respected, so their approval should significantly increase our chances of being recognised in our target market.

- Interbots have built an initial caring brand image in the autism market, which is aligned with the brand image that we are trying to establish. 
How 'Interbots' would benefit from partnering with us:

- Gives them a greater product range. The more range of products a company has the better chance they have of getting into retail stores (Inventors journal, 2011).

- Eliminates us as a competitor.

- If we acquire a patent for features that have been developed since our prior public disclosure, Interbots will share our exclusive rights in these technologies.

\section{Creating a partnership with therapists who work with children who have autism.}

Creating a partnership with therapists would give us the following advantages:

- Potential customers feel more comfortable purchasing a product that was recommended to them by a therapist.

How therapists would benefit from us:

- They would receive large discounts on our products.

- Their services will be recommended to our customers on our website.

\section{Market Analysis}

\section{Children with Autism:}

Autism spectrum disorder is a development disorder that often affects social abilities. (Anderson, 2013). Children with autism find it hard to distinguish between positive and negative behaviours. They are often unaware of the consequences of their actions. (Behaviour difficulties, 2007). Children with autism learn differently from other children. A new study, conducted at 'Hopkins' university revealed that children with autism seem to rely more on their own internal sense of body position, whereas most children rely on visual information. The study concluded that the more a child relies on their internal sense, the greater the child's impairment in relation to socialising and motor skills. (Different ways Autistic children Learn, 2013).

\section{Technology and Autism:}

Robotic toys and software technologies such as apps have the potential to be useful support tools for children with autism because they find it difficult to socialise with other people. Human interaction is 
very unpredictable and this fact can be very overwhelming for any child, let alone a child with autism. Technology is programmed and predictable, which is why children with autism find it easy to process information provided by software. Thus it has been observed that many children with autism are drawn to technology. However some experts are not satisfied that technological devices are a good tool for teaching children with autism positive social behaviour. Haifa University Professor Tamar Weiss, a leading expert on the use of technology in autism said in a "Times of Israel" article that technological devices such as iPads can appear to help draw autistic kids out of their shell, but sometimes they have the the opposite effect of causing autistic children to become so preoccupied with the device, that they completely ignore social interaction. (Why use Robots, 2013).

\section{Robots used as a teaching tool for children with Autism:}

Studies by lead scientist have shown that robotic toys can help autistic children learn the social skills, which they sometimes lack. In a study led by Dr Kerstin Dautenhahn and lain Werry of the University of Hertfordshire, fifteen autistic children aged between five and fifteen were given a robotic toy to play with for two weeks. They concluded that each child displayed some kind of social interaction with the toy. The same scientists also did an earlier study with eighteen children, half of the children played with a robotic truck and the other half interacted with a non-robotic truck. The children who played with the robotic truck began to communicate with one another. (Robot-human Interactions, 2002).

\section{Therapists use Robotics and other technologies as teaching tools.}

A study conducted on nineteen children with autism while they visited a therapist by researcher Joshua Diehl, an assistant professor of psychology at the University of Notre Dame in Indiana found that a child with autism shows more progress in therapy session, where a robot toy is used. (Behaviour difficulties, 2007).

At the present time there is still not enough research co conclusively prove the effects of robots on children with autism. However the research so far conducted seems to suggest that robotic toys have the potential for revolutionising the way children with autism learn positive social behaviour. (Doll new cure for Autism, 2012).

\section{Applied Behaviour Analysis (ABA) Therapy:}

Through decades of research, the field of behaviour analysis has developed many techniques for increasing useful behaviours and reducing those that may interfere with learning. $A B A$ is the use of these techniques to bring about positive change in behaviour. 
Many toys and tools are used in ABA therapy, for example lollies are used to reward children for positive behaviour. If a child shows positive behaviour they are rewarded with a lolly, indicating to the child that their behaviour is positive. (Newman and Hammond 2005).

Why our Toy is suitable for ABA therapy: The toy is designed to cease responding to any loud sounds or inappropriate actions that a child with autism is sometimes prone to. For example if the child screams or hits the toy, it stops moving, indicating to the child that their behaviour is negative. As the child begins to play appropriately, i.e. gentle stroking and speaking in a soft voice, the toy will resume motion indicating to the child that their behaviour is now positive and therefore worthy of interaction. The rewarding aspect of the toy makes it a great fit for 'ABA' therapy.

\section{Market Research}

Primary research: Overall we talked to fifteen parents and twenty therapists to help get an insight into our target market. In addition we talked to ten teachers and five caregivers of children with autisms. This research confirmed that the problem which we are addressing is very important to the autism community. After talking to parents of children with autism we identified an additional problem. The parents said that there is a lack of 'respite care' available to them. Fourteen out of fifteen parents said that they were less than moderately happy with the respite care available. "Respite care" is the temporary institutional care of a sick, elderly, or disabled person, which relieves the usual care. (Respite care Definition, 2013).

Secondary research had also indicated that this was a problem. A recent study in the US looked into the resources and services available for treating autism. The study was done through the distribution of 1,500 surveys throughout the US. $26 \%$ were generally happy. However, even those who were generally happy with the services and resources indicated that they were unhappy with the respite services (Best Places to Live if you have Autism, 2013). Our toy could potentially be used as a form of respite care. It could potentially keep the child's attention for a short period every day, while the parent takes a mental break.

Our research also enabled us to identify a second additional problem that the toy could potentially address. Children find it hard to transition into new surroundings, i.e. transitioning from home to school. It can take an autistic child a long time to adjust. Many parents of children with autism have said that having a toy their child likes with them, makes the transition easier. (Sending my autistic son to preschool, 2009). 


\section{References}

ABA (2013). Retrieved April 2nd 2013 from http://www.autismspeaks.org/whatautism/treatment/applied-behavior-analysis-aba.

Access your options for growth. (2013). Retrieved September 8th 2013 from http://www.infoentrepreneurs.org/en/guides/assess-your-options-for-growth.

Autism insurance mandate extension signed by Governor Jerry Brown. (2013, October $\left.10^{\text {th }}\right)$.

Retrieved September 8th 2013 from

http://article.wn.com/view/2013/10/10/Autism_insurance_mandate_extension_signed_by_Govern or_Jerry.

Autism in the US (2013) Retrieved May 4th 2013 from

http://www.medicalnewstoday.com/articles/257959.php.

Autism New Zealand. (2013) Retrieved July $8^{\text {th }} 2013$ from

http://www.schoolnews.co.nz/education/295-student-support/1105-autism-spectrum-disorder-aninvisible-disability.

Behaviour difficulties (2007). Retrieved November 4th 2013 from

http://www.supernanny.co.uk/Advice/-/Health-and-Development/-/Special-Needs/Behaviour-and-

Discipline-issues-for-children-with-Autistic-Spectrum-Disorders.aspx.

Best Places to Live if you have Autism (2013) Retrieved April 11th 2013 from

http://www.autismspeaks.org/about-us/press-releases/10-best-places-live-if-you-have-autism.

Buchen, L. (2011, November) Scientists and autism. Retrieved September 15th 2013 from

http://www.nature.com/news/2011/111102/full/479025a.html.

Business strategies. (2013).Retrieved July 12th, 2013 from

http://www.businessplanadvice.com/strategies.asp.

Campling, P. W. (2008). Management: 3rd Asia Pacific Edition. Queensland: Wiley

Pearson (2013) First mover advantage. Retrieved January $18^{\text {th }} 2013$ from

http://www.pearsoned.co.uk/Bookshop/article.asp?item=312

Dautenhahn, K., Werry, I. (2002). A Quantitative technique for analysing robot-human

Interactions. International Conference on Intelligent Robotsand Systems: Lausanne, 1132-1138.

Doll new cure for Autism (2012) Retrieved April 16 2013 from

http://www.dailymail.co.uk/health/article-147262/Could-playing-doll-new-cure-autism.html.

Hall, E.T. (1990) The hidden dimension. Published by Anchor.

Heasley, S (2013, April $\left.8^{\text {th }}\right)$ Respite care impact. Retrieved April 11th 2013 from

http://www.disabilityscoop.com/2013/04/08/respite-care-autism-parents/17659.

Hofstede's cultural dimensions. (2013). Retrieved March $8^{\text {th }} 2013$ from http://geert-

hofstede.com/dimensions.html.

How much is ABA therapy. (2012). Retrieved August $12^{\text {th }} 2013$ from

http://community.babycenter.com/post/a32001509/how_much_is_aba_therapy.

Impact for Autism parents http://www.disabilityscoop.com/2013/04/08/respite-care-autismparents/17659. 
Interbots partnership (2012). Retrieved July 4th 2013 from

http://medcitynews.com/2012/05/company-develops-robot-to-help-autistic-children-learn-socialreference-skills.

Inventors journal (2011). Retrieved April 2nd 2013 from

http://www.asktheinventors.com/invent.html.

J, Anderson (2013) Imitation and Children with Autism. Retrieved November 2nd 2013 from http://www.gse.harvard.edu/news-impact/2013/04/imitation-and-children-with-autism-lauraedwards.

Llopia, G. (2013, May 13) Capturing sensitive Market Will Require More Than a Total Market Strategy. Retrieved September 8th 2013 from www.forbes.com.

Lynn, B. (1995). Building Brand Identity A Strategy for Success in a Hostile Marketplace. John, Wiley.

Mercola (2013, April $\left.2^{\text {nd }}\right) C D C$ say. Retrieved November 4th 2013 from

http://articles.mercola.com/sites/articles/archive/2013/04/02/autism-rates.aspx

Newman, B., Hammond, T. (2005) Straight Answers to Your ABA Programming Questions. Kindle ISBN: 978-1-61550-793-1.

Norton, A (2013) Kelly the Robot Helps Kids Tackle Autism. Retrieved August 14th 2013

fromhttp://consumer.healthday.com/cognitive-and-neurological-health-information-26/autismnews-51/kelly-the-robot-helps-kids-tackle-autism-675997.html.

Product led (2013). Retrieved August $18^{\text {th }}$ from

http://www.businessdictionary.com/definition/product-led.html.

Respite care Definition (2013) Retrieved April 10th 2013 from

http://www.oxforddictionaries.com/definition/english/respite-care.

Sending my autistic son to preschool (2009). Retrieved September $11^{\text {th }} 2013$ from

http://www.circleofmoms.com/autismaspergerspdd-awareness/sending-my-autistic-son-to-preschool-357981.

Stresses on Families (2000). Retrieved April 2nd 2013 from http://oreilly.com/medical/autism/news/stress_family.html.

Webber, S. \& Tether, C. (2007).Baseline review of Angel investment in New Zealand. Ministry of Economic Development, July, http://www.med.govt.nz/aboutus/publications/publications-bytopic/evaluation-of-government-programmes/archive/report.pdf.

Why use Robots (2013). Retrieved April $18^{\text {th }} 2013$ from

http://newswithtags.com/Robotics/altview-co-altview--why-use-robots-with-autisticchildren\#.UaVRakDdcVQ.

Wolf, R.C. (2000) Effective international joint venture management .Printed in the United States of America. Library of congress cataloguing-in- publication data.

World robots. (2013). Retrieved August $12^{\text {th }} 2013$ from http://www.freedoniagroup.com/brochure/29xx/2950smwe.pdf. 


\section{Contents}

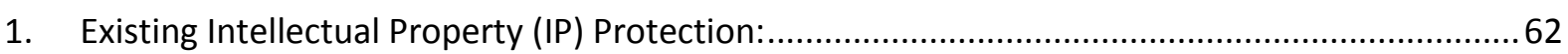

a) IP Protection that the toy does not currently have: .................................................................62

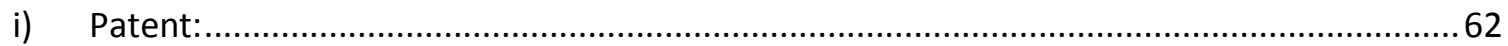

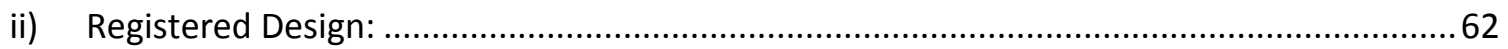

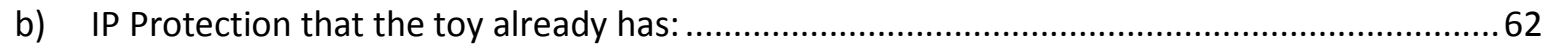

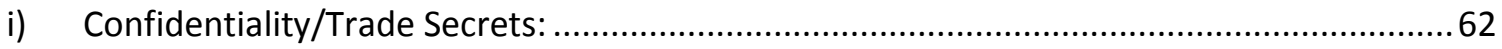

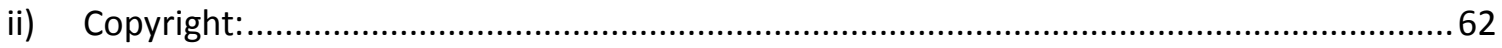

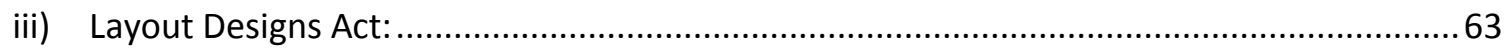

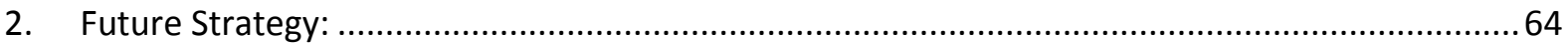

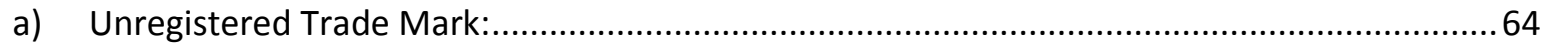

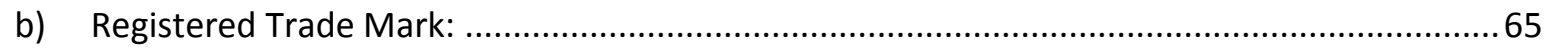

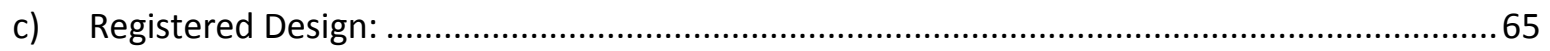

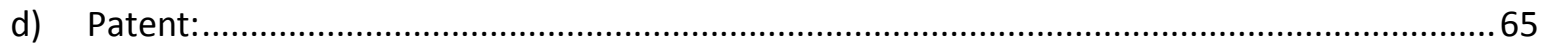

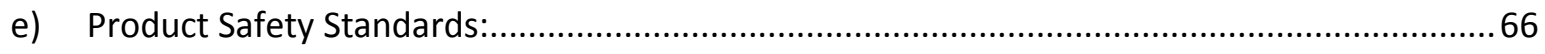

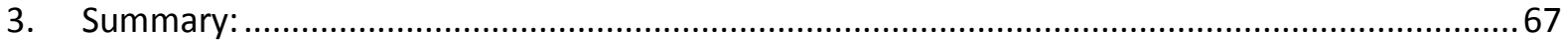




\section{Existing Legal Protection and Strategy for the Foreseeable Future}

\section{Existing Intellectual Property (IP) Protection:}

a) IP Protection that the toy does not currently have:

i) Patent:

The toy was disclosed in the public domain at an exhibition prior to an application for a patent being filed. Furthermore, pictures and information were published on the internet. Therefore the invention can no longer be said to be new, which is a requirement for patentability. ${ }^{1}$

ii) Registered Design:

The toy's design was published on the internet, therefore this design is no longer new, which is a requirement for registration. ${ }^{2}$

b) IP Protection that the toy already has:

i) Confidentiality/Trade Secrets:

Since its public disclosure, the toy has been continually developed and as such new knowledge and information has accrued. Therefore during the current development stage, all those working on or with the toy, have signed confidentiality agreements and are thus under an obligation of confidence.

- Limitations:

$>$ Nothing can be done under breach of confidence in relation to the confidential information if it found itself in the hands of a third party who did not know that the information was subject to a confidentiality agreement.

Once the toy enters the open market, its functional features will become vulnerable to reverse engineering because at this point the toy will have entered the public domain. However the intellectual capital, such as the particular manufacturing process can remain a trade secret.

ii) Copyright:

Copyright is automatically acquired in NZ when one creates an original work. In the Copyright Act 1994, the word "work" is used to refer to forms of creative expression. NZ copyright law categorises the output of creative expression.

\footnotetext{
${ }^{1}$ Patents Act 2013, s 14.

${ }^{2}$ Designs Act 1953, s 5(2).
} 
There are three categories which are potentially applicable to the toy. The first is: "industrially applied artistic work". The time span of copyright protection under this category is sixteen years from the date when more than fifty copies of the work have been made in three dimensions for the purpose of sale or hire. ${ }^{3}$

The second potential category is: "work of artistic craftsmanship". It is far less likely that toy can be categorised as such. However it would be favourable as this type of copyright lasts for 25 years from the time when the work was made. ${ }^{4}$

The third category will be applicable to the toy once the proposed software is created. In NZ, computer programs are included in the definition of literary works. ${ }^{5}$

- Limitations:

$>$ Few other countries offer protection for industrially applied artistic work under their copyright laws. The United States of America (US) has been identified as a potential target market for the toy outside of NZ. US copyright law excludes from protection designs that are used for useful articles and that are not identifiable separately from, or cannot exist independently of, the utilitarian aspects as a work of art. ${ }^{6}$ Therefore it is very likely that it will be necessary to obtain a US design patent, if the toy's design is to be protected in the US.

NZ copyright law explicitly permits decompilation of software. ${ }^{7}$ In the US case of Atari Games Corp v Nintendo of America Inc, it was also held to be a fair use. ${ }^{8}$

iii) Layout Designs Act:

The Layout Designs Act 1994 provides protection for owners of integrated circuits and layout designs. This protection mode is similar to copyright as it is also automatically acquired provided that the originality threshold is met.

The layout design cannot have been commonplace at the time it was made. ${ }^{9}$ The toy has integrated circuits within its internal mechanisms. These circuits are laid out in a manner that is unlikely to be deemed commonplace as the functions which they dictate, appear to be original.

\footnotetext{
${ }^{3}$ Copyright Act 1994, s 75(4)(a).

${ }^{4}$ Copyright Act 1994, s 75(1)(c).

${ }^{5}$ Copyright Act 1994, s 2(1)(b).

${ }^{6}$ Copyright Act 17 U.S.C. $\S 101$.

${ }^{7}$ Copyright Act 1994, s 80A(1).

${ }^{8}$ Atari Games Corp v Nintendo of America Inc. 975 F.2d 832 (Fed. Cir. 1992).

${ }^{9}$ Layout Designs Act 1994, s 6.
} 
The same protection can be acquired in the US under the Semiconductor Chip Protection Act 1984.

- Limitations:

$>$ Reverse engineering, although not termed as such is listed as a fair use right in the Layout Designs Act $1994 .^{10}$

$>$ A person will not be in breach of the owner's exclusive right to commercial exploitation if at the time of acquiring the unauthorised integrated circuit they were unaware and could not have been reasonably expected to know that the integrated circuit was unauthorised. ${ }^{11}$

\section{Future Strategy:}

a) Unregistered Trade Mark:

In the event that the toy enters the marketplace prior to a trade mark being registered, protection may be acquired in NZ, once sufficient goodwill is generated. This requires significant consumer exposure. Therefore a substantial amount of time is required for goodwill to be generated.

However in the meantime it may be possible for the unregistered mark to acquire protection under the Fair Trading Act 1986. A trader is able to enforce s 9 against a competitor without having to prove their own goodwill or reputation. This is because the section is concerned with consumer protection. Therefore if the consumer is being misled or deceived, that will be enough for enforcement of the section.

- Issues to think about:

i) Before an action for passing off can be brought against a rival competitor, the aggrieved trader must first prove that they have a protectable goodwill. ${ }^{12}$ Also the fact that goodwill need not be shown under the Fair Trading Act 1986 is only a theoretical distinction. In practice evidence of reputation is nonetheless required in a Fair Trading Act action if there is an alleged confusion of names. Therefore it is certainly worth registering a trade mark because it makes it a lot easier to prove infringement. Instead of having to prove goodwill, one need only point to the register.

ii) The Fair Trading Act 1986 is a NZ statute and therefore cannot be enforced in relation to overseas trade. It is also inconceivably difficult to establish passing off if the infringement occurs in another country prior to the aggrieved trader having begun trading in that country.

\footnotetext{
10 Layout Designs Act 1994, s 18.

${ }^{11}$ Layout Designs Act 1994, s 15(1).

12 IR Commers v Muller \& Co's Margarine Itd [1901] AC 217 (HL) at 223-224.
} 


\section{b) Registered Trade Mark:}

Since the plan is to potentially sell the toy in the US as well as NZ, it is advisable that a mark in the form of a name and logo is registered in both countries.

- Issues to think about:

i) There is a potential issue with the descriptive nature of the name. ${ }^{13}$ The name stems from the word autistic therefore it is arguably too descriptive and insufficiently distinctive for registration.

ii) The name may be unfavourable with the target market. A trade mark may be opposed on the ground that it is likely to offend a significant section of the community. ${ }^{14}$ There is a risk that the name will be considered offensive in the autism community.

\section{c) Registered Design:}

The toy's design should be registered because US copyright law does not provide protection for industrially applied artistic work. Equivalent protection is provided for in the US in the form of a design patent. ${ }^{15}$ The design patent is essentially the same as a registered design in NZ.

However the design as it existed during the public disclosure cannot be registered. Therefore it is advisable that the design be substantially changed so that it can be registered.

- Issue to think about:

i) If the design is changed now, so that it is substantially different to the extent that it could once again be deemed original for the purposes of registration, it would nonetheless lose the status of being substantially novel. Therefore in the event that it is revealed upon the conclusion of the product testing that successful interaction with the children is largely due to the toy's functional features, which is highly likely, it is advisable that the design is drastically changed to the extent that it is once again substantially novel.

d) Patent:

A patent can be obtained in those elements of the toy which were developed since the public disclosure and that meet the requirements of a patentable invention. Aside from being new, these elements will also need to be useful and they require an inventive step. ${ }^{16}$

\footnotetext{
${ }^{13}$ Trade Marks Act 2002, s 18(1)(c).

14 Trade Marks Act 2002, s 17(1)(c).

${ }^{15}$ Patents Act 35 U.S.C. § 173.

16 Patents Act 2013, s 14,
} 
- Issues to think about:

i) The proposed software which is one of the features that was not developed at the time of the public disclosure cannot be protected. ${ }^{17}$ However inventions which have embedded software will remain patentable. Although the planned for software will be embedded, it is still unpatentable because the toy itself cannot be patented due to the prior public disclosure.

ii) Many small to medium sized manufacturing companies see patents as being an expensive protection mode that provides a limited benefit.

\section{e) Product Safety Standards:}

The Product Safety Standards (Toys) Regulations 2005 deems it necessary for toys intended for use by children who are up to 36 months of age to comply with the Standard AS/NZS ISO 8124.1:2002. Any breach of the Standard means that the regulation is also breached and this is an offence under the Fair Trading Act. ${ }^{18}$

- Issues to think about:

i) It is not possible to simply label the toy as not being suitable for children under 36 months of age. If the child is physically and intellectually capable of playing with the toy in the way it was intended to be used, then it will be deemed as a toy designed for children under 36 months of age. ${ }^{19}$ The toy is simple to use and testing with small children will likely show that they are capable of using the toy in the way in which it is meant to be used. Thus it is highly likely that the Standard will apply regardless of whether there is a minimum age label attached to it.

ii) The standard prohibits the supply of small toys or toys with small parts, which can be swallowed or inhaled by children under 36 months of age. ${ }^{20}$ The toy is large, however it contains multiple small parts on the interior. A reasonably foreseeable abuse test simulates conditions in which abuse could occur. Given the particular target market, it may be necessary to test the toy in conditions where it is thrown, as children with autism, are sometimes prone to such behaviour.

iii) Another potential hazard is the fur that covers the toy's exterior shell. It will be necessary to conduct testing to ensure that the attached fur does not come away in the event that it is chewed, pulled or sucked. Alternatively it may be worth considering using a different covering material altogether.

\footnotetext{
${ }^{17}$ Patents Act 2013, s 11(3).

${ }^{18}$ Fair Trading Act 1986, s 30.

19 "Children's Toys: A Guide to Complying with the Product Safety Standard" (2009) Commerce Commission New Zealand at $2<w w w . c o m c o m . g o v t . n z>$.

20 Ibid, at 1.
} 


\section{Summary:}

- Existing Protection:

$>$ Confidentiality: All persons who have signed confidentiality agreements are under an obligation of confidence. Protection also extends to those that obtained information in circumstance that impart an obligation of confidence (clearly confidential situations). Protection does not extend to third parties who obtained information without the knowledge that it was disclosed in breach of confidence.

$>$ Copyright: The toy has automatically acquired copyright protection in NZ. The toy is most likely to be categorised as an industrially applied artistic work. There is no equivalent category of protection under US copyright. In the US this type of protection is obtainable under a design patent.

$>$ Layout Designs Act: Provides another automatic source of protection. This protection mode applies to the integrated circuits within the toy's internal mechanisms. Reverse engineering of these integrated circuits is a fair use under the Layout Designs Act 1994.

\section{- Future Strategy:}

$>$ Unregistered Trade Mark: an unregistered trade mark is protectable in NZ under the Fair Trading Act 1986 and under the tort action of passing off, once it can be shown that the there is goodwill associated with the mark. Goodwill is acquired through trade and sufficient publicity. Therefore usually a substantial amount of time in the market place is required before the requisite goodwill is accrued. Furthermore these methods are inappropriate for dealing with potential infringement that occurs outside of NZ. As such, it is advisable that a trade mark is registered a short time before the toy enters the market.

$>$ Registered Trade Mark: The name is potentially insufficiently distinctive and there is also the danger that it is offensive to the target market. Therefore it is advisable that a less controversial name is chosen. The Madrid Protocol, allows applicants to file a single application for registration designating at once all the countries where protection is sought. Therefore the name and logo should be registered in the US as well as NZ.

> Registered Design: It advisable that the design be drastically changed so that it is once again substantially novel. If this is done the new design can be registered in NZ. It will also make it possible to acquire a Design Patent in the US.

$>$ Patent: Can be obtained for any of the newly developed features since the public disclosure, provided that these meet the requirements of a patentable invention. However it is only advisable that a patent be obtained for any such feature if it is truly an innovate invention that is worth protecting. In NZ this protection mode no longer applies to software as such, under the Patents Act 2013. 
Product Safety Standards: In order to ensure compliance with the relevant safety standard, it will be necessary to conduct a series of tests. It is advisable that the toy is dropped as well as thrown to ensure that small parts, which are capable of being swallowed or inhaled are not broken off in such instances. Furthermore the fur covering the toy should be tested to see that it does not come away when being chewed, pulled or sucked. It is advisable that an alternative material is found to cover the toy's exterior shell. 